\title{
Genome-wide transcriptome profiling and spatial expression analyses identify signals and switches of development in tapeworms
}

Peter D. Olson ${ }^{1 *}$, Magdalena Zarowiecki ${ }^{1,2}$, Katherine James $^{1}$, Andrew Baillie' ${ }^{1}$, Georgie Bartl ${ }^{1}$, Phil Burchell ${ }^{1}$, Azita Chellappoo', Francesca Jarero ${ }^{1}$, Li Ying Tan ${ }^{1}$, Nancy Holroyd ${ }^{2}$ and Matt Berrimann ${ }^{2}$

\begin{abstract}
Background: Tapeworms are agents of neglected tropical diseases responsible for significant health problems and economic loss. They also exhibit adaptations to a parasitic lifestyle that confound comparisons of their development with other animals. Identifying the genetic factors regulating their complex ontogeny is essential to understanding unique aspects of their biology and for advancing novel therapeutics. Here we use RNA sequencing to identify up-regulated signalling components, transcription factors and post-transcriptional/translational regulators (genes of interest, GOI) in the transcriptomes of Larvae and different regions of segmented worms in the tapeworm Hymenolepis microstoma and combine this with spatial gene expression analyses of a selection of genes.
\end{abstract}

Results: RNA-seq reads collectively mapped to $90 \%$ of the $>12,000$ gene models in the H. microstoma v. 2 genome assembly, demonstrating that the transcriptome profiles captured a high percentage of predicted genes. Contrasts made between the transcriptomes of Larvae and whole, adult worms, and between the Scolex-Neck, mature strobila and gravid strobila, resulted in $4.5-30 \%$ of the genes determined to be differentially expressed. Among these, we identified 190 unique GOl up-regulated in one or more contrasts, including a large range of zinc finger, homeobox and other transcription factors, components of Wnt, Notch, Hedgehog and TGF- $\beta$ /BMP signalling, and post-transcriptional regulators (e.g. Boule, Pumilio). Heatmap clusterings based on overall expression and on select groups of genes representing 'signals' and 'switches' showed that expression in the Scolex-Neck region is more similar to that of Larvae than to the mature or gravid regions of the adult worm, which was further reflected in large overlap of up-regulated GOI.

Conclusions: Spatial expression analyses in Larvae and adult worms corroborated inferences made from quantitative RNA-seq data and in most cases indicated consistency with canonical roles of the genes in other animals, including free-living flatworms. Recapitulation of developmental factors up-regulated during larval metamorphosis suggests that strobilar growth involves many of the same underlying gene regulatory networks despite the significant disparity in developmental outcomes. The majority of genes identified were investigated in tapeworms for the first time, setting the stage for advancing our understanding of developmental genetics in an important group of flatworm parasites.

Keywords: Hymenolepis, Tapeworms, RNA-seq, Transcriptomics, Differential gene expression, Transcription factors, Signalling factors, Post-transcriptional regulators

\footnotetext{
*Correspondence: p.olson@nhm.ac.uk

${ }^{1}$ Division of Parasites and Vectors, Department of Life Sciences, The

Natural History Museum, Cromwell Road, London SW7 5BD, UK

Full list of author information is available at the end of the article
} 


\section{Background}

Tapeworms are parasitic flatworms (Platyhelminthes) characterised by complex life cycles and a segmented, or strobilar, body plan, considered to be evolutionarily novel adaptations to parasitism [1-3]. As agents of neglected tropical diseases, they are estimated to be responsible for over 2.8 million disability-adjusted life years [4] and account for up to $30 \%$ of cases of epilepsy in regions of high endemicity [5]. Less acute, but more prevalent and widespread cestodiases caused by Hymenolepis species and other tapeworms contribute to further morbidity, particular of children, and frequently co-occur with other helminth infections [6]. The dwarf tapeworm, H. nana, is the most commonly reported cestode in humans [7] and has been shown to be the causative agent of proliferative, metastatic 'tumours' in immunosuppressed individuals, making its ubiquity especially important in areas where there is high prevalence of HIV AIDS [8, 9].

The genetic signals and switches that underpin the complex development of parasitic flatworms have just begun to be investigated [10-12] despite their diversity in form, ontogeny and potentially unique somatic stem cell systems [13-15] that are central to their life histories and the diseases they cause $[16,17]$. In contrast, free-living planarian flatworms have been classical models in developmental biology for well over a century, and in the last two decades the availability of genomic resources [18, 19], functional methods [20-22] and a wide range of celltype markers in Schmidtea mediterranea have made planarians a preeminent model system for investigating the biology of regeneration [23]. Their somatic stem cells [24, 25], called neoblasts, have been studied intensively [26], and neoblast-like proliferative cell compartments underpin the development of all flatworms [27]. Gene regulatory networks that pattern their axes during growth and regeneration have been elucidated [28], including the seminal discovery of canonical Wnt signalling as the basis for head/tail decision-making [29-31]. This rapidly growing canon of literature provides an important framework for comparative investigations of gene regulation in other flatworms and will help to ameliorate the historic gulf between the fields of development and parasitology [10].

More recently, genomic resources [32-35] and methods for investigating gene expression have been developed in trematode (fluke) and cestode (tapeworm) model systems, including the human bloodfluke Schistosoma mansoni, the fox tapeworm Echinococcus multilocularis and the mouse bile-duct tapeworm Hymenolepis microstoma. Somatic stem cells are central to the complex life cycles of flukes and tapeworms, and neoblast-like proliferative cell compartments have been characterised in both groups [14, 15, 36, 37]. New tissue and organ-specific markers have been developed for use with confocal microscopy [38, 39] as have colorimetric and fluorescent in situ hybridisation methods for examining spatial gene expression [15, 40]. Genomic resources and empirical tools are thus now available to facilitate the study of their developmental genetics, enabling more direct comparisons with free-living flatworms and more distantly related animal groups.

Few previous attempts have been made to identify the genetic factors regulating major developmental processes in tapeworms such as strobilation or larval metamorphosis. Prior to the advent of whole-genome sequencing methods, Bizarro et al. [41] employed empirical cDNA subtraction to address the process of strobilation, comparing differentially expressed genes in tetrathyridia and segmenting adults of Mesocestoides corti. Functional characterisation of the transcripts showed significant differences between the samples across the entire range of cellular processes, but pre-NGS methods only enabled a small number of factors to be identified. Here we use quantitative, whole-genome transcriptome profiling of the tapeworm Hymenolepis microstoma [42] to identify differentially expressed (DE) genes in Larvae and adults, and in the 'Scolex-Neck', 'Mid' and 'End' regions of the strobilar worm, broadly encompassing the major phases of development in the typical tapeworm life cycle (Fig. 1a). RNA-seq data were mapped to the $H$. microstoma genome (version 2), and details of this update to the published version 1 assembly [35] are presented here for the first time. Contrasts were made among the samples to identify DE signalling components (e.g. ligands and receptors) and transcription factors, often broadly referred to as 'developmental control genes' [43], as well as post-transcriptional/translational regulators, reasoning that these broad categories of genes are likely to include key regulators of the underlying developmental processes. Whole-mount in situ hybridisation (WMISH) in Larvae and adult worms was used to elucidate the spatial expression of a selection of these 'genes of interest' (GOI), enabling their expression to be linked to tissues, regions or organs in tapeworms for the first time. We present an overview of the sample transcriptome profiles and sets of DE gene models, and discuss factors examined by WMISH in detail, using their putative identities and spatial patterns together with published accounts of orthologs in planarians and/or other animals to infer potential roles of the gene products in tapeworms.

\section{Results and discussion}

\section{The Hymenolepis microstoma v.2 genome}

Our analyses utilised the unpublished v.2 release of the $H$. microstoma genome which is based on the inclusion 


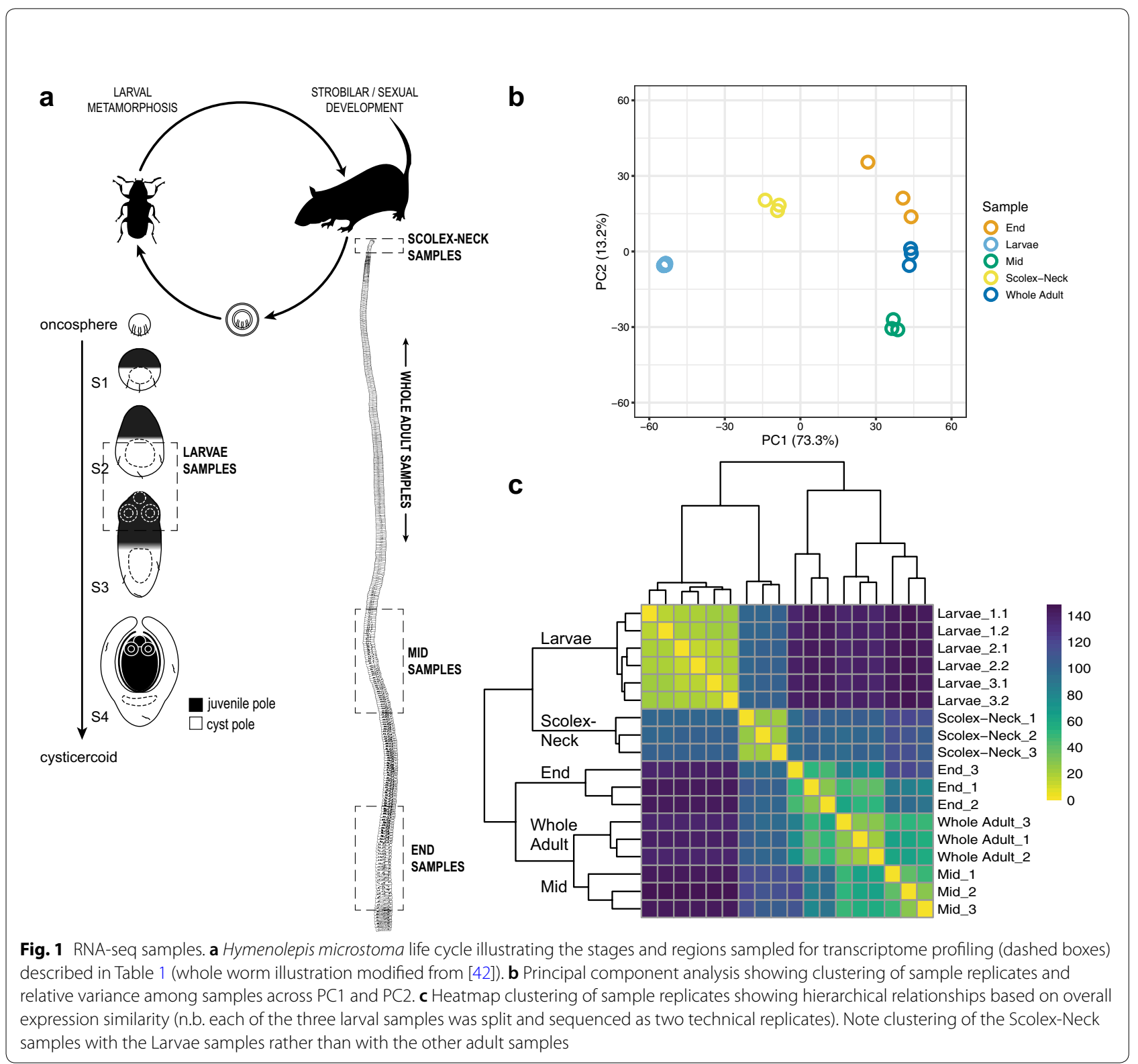

of an additional Illumina HiSeq lane of data and reassembly of the v.1 genome as described in Methods. In comparison with the v.1 genome published in Tsai et al. [35], the new assembly is larger (182 MB) and contains over 2,000 additional gene models supported by a combination of empirical RNA-seq data and bioinformatic predictions. All genome and gene model data are available online via WormBase ParaSite (WBP) (parasite. wormbase.org; [44, 45]) which includes a wide suite of bioinformatic tools for data access and interrogation, including the ability to dynamically generate gene trees and motif annotations using the most recent release of WBP and other major sequence databases.

\section{Sample overview}

Biological characteristics of the samples in relation to development and metrics associated with their transcriptome profiles are given in Table 1, and the sample regions are illustrated graphically with respect to the $H$. microstoma life cycle in Fig. 1a. Mapping of the RNAseq data to the genome resulted in $90 \%$ of the 12,371 gene models having normalised counts of one or more in at least one sample replicate, indicating that the transcriptome profiling captured the majority of predicted 


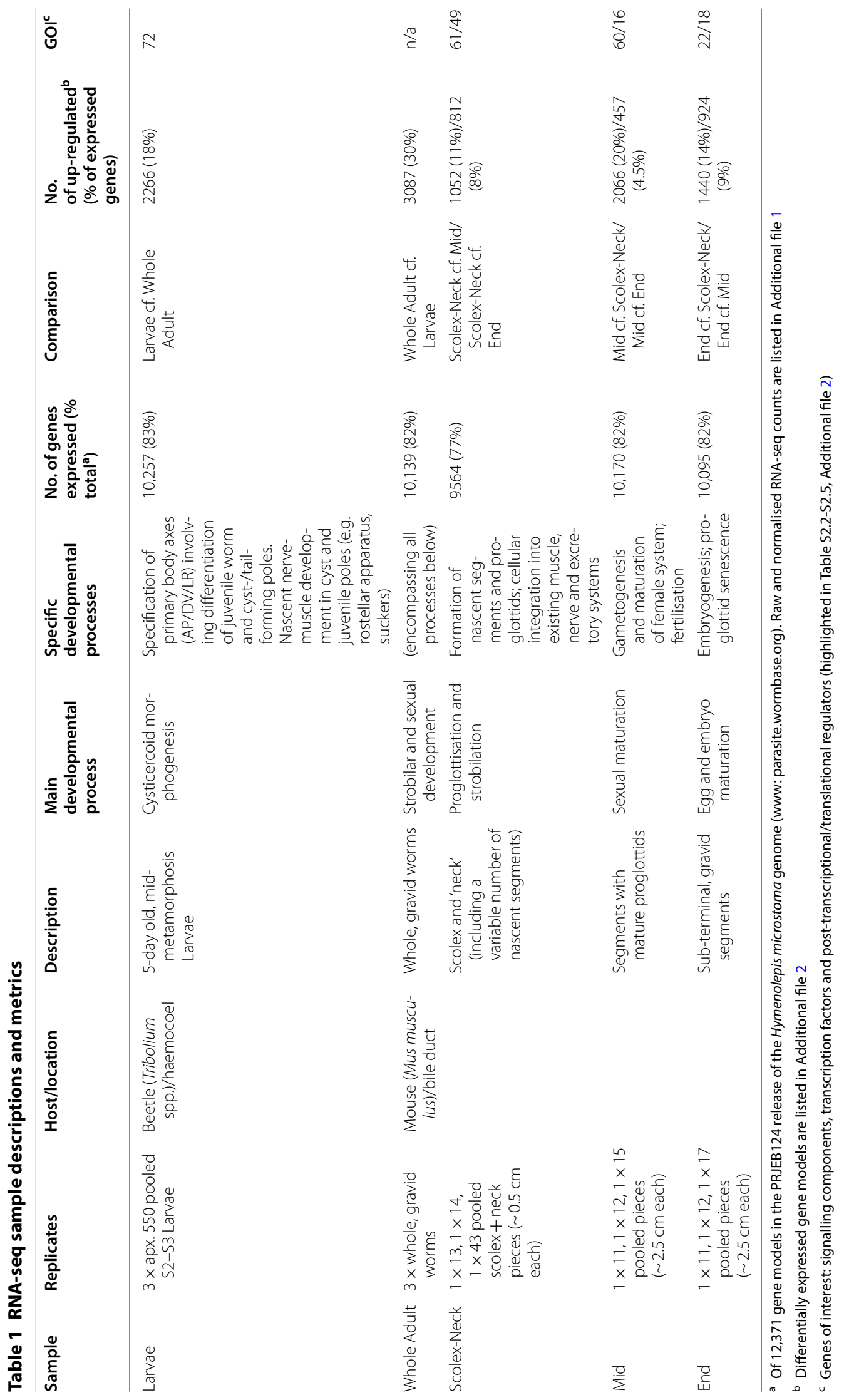


protein-coding genes. The overall percentage of models expressed was nearly identical among samples (82-83\%), save the Scolex-Neck in which it was $~ 5 \%$ less (77\%; Table 1). Full listings of raw and normalised counts are given in Additional file 1: Tables S1.2 and S1.3, respectively.

Principal component analysis of the sample replicates (Fig. 1b) showed that they cluster tightly, save the End samples that showed a higher degree of dispersion. Eighty-six percent of the total variation was characterised by the first two principal components, with PC1 broadly separating the Larvae and Scolex-Neck samples from the Mid, End and Whole Adult samples, and PC2 separating the Mid and End samples from the others. The degree of similarity among replicates was higher than might have been expected, given that all samples were based on multiple individuals (save the Whole Adult samples; Table 1) and that there was inherent variability in both the degree of development among Larvae (which nevertheless showed the least dispersion) and in the ability to sample precisely the same regions of the strobila from different individuals. Heatmap analysis of sample-to-sample distances (Fig. 1c) showed that the Scolex-Neck samples were more similar in overall expression to the Larvae than to the other adult samples. Meanwhile, the Mid, End and Whole Adult samples formed a nested relationship in which the Whole Adult samples were closest to the Mid samples, suggesting that the profiles for Whole Adults were dominated by factors relating to sexual development, as would be expected given the proportion of the adult worm represented by the strobila.

To examine similarities and differences among the samples in relation to our GOI, we constructed heatmaps based on normalised, mean expression values of three suites of genes: all homeobox transcription factors (Fig. 2a), components of Wnt, Notch and Hedgehog signalling pathways (Fig. 2b) and the GOI identified here (Fig. 2c), discussed below. In all cases, clustering of the samples produced the same branching pattern as the sample-to-sample comparisons based on all gene models. Moreover, hierarchical clustering united the ScolexNeck and Larvae as sister groups, whereas independent branches would be more likely if their relationship was simply a reflection of their relative dissimilarity to the other samples. This relationship was further illustrated by large overlap in GOI DE in both the Larvae (cf. Whole Adults) and Scolex-Neck (cf. Mid and/or End) samples (Table 2; Additional file 1: Table S1), discussed below. We suggest that these groupings reflect the overarching similarities and differences in the underlying developmental processes represented by the samples (Table 1): mid-metamorphosis Larvae and the neck region of adult worms both exhibit extensive tissue re-modelling and patterning, whereas the Mid and End, and consequently, Whole Adult samples, exhibit growth predominately in relation to sexual and reproductive development.

\section{Overview of differentially expressed genes}

We considered a gene model to be differentially expressed if the difference between the mean, normalised sample counts was greater or less than zero at a confidence level of 1e-05, irrespective of the magnitude of difference. We ranked results by their log2fold change but did not impose an arbitrary cut-off to limit the number of DE genes taken into consideration. To identify up-regulated genes in the Larvae, we contrasted it with the Whole Adult sample, and not with the regional adult samples. To identify DE genes in adults, we made independent contrasts of each of the three regional samples with the other two, enabling DE gene models to be associated with different phases of strobilar and sexual development that are confounded by the Whole Adult sample. Full lists of DE gene models are given in Additional file 2: Tables S2.2-S2.5 for both sides of each contrast. For the reasons above, gene models up-regulated in the Whole Adult relative to Larvae are not considered further here but are included in Additional file 2: Table S2.2.

The percentage of gene models DE among the contrasts ranged from as low as $4.5 \%$ in the Mid sample (cf. End) to $30 \%$ in the Whole Adult sample (cf. Larvae; Table 1). The majority of the highest DE genes (e.g. top 20) among the contrasts were 'novel' proteins: predicted protein sequences lacking any significant similarity against the BLAST nr database (i.e. $e$ values $<0.0001$ ) or recognisable protein domains that were variously annotated as ' $n / a$ ' (no annotation), 'expressed protein', 'expressed conserved protein' (when supported by $>100$ RNA-seq reads [35]), 'hypothetical protein' or 'hypothetical transcript'. Putatively novel proteins make up just over half of all gene models (6455 of 12,371) and among contrasts ranged from 31 to $47 \%$ of the DE genes. In general, there were $\sim 10 \%$ more novel gene models DE in contrasts involving the Whole Adult, Mid or End samples as compared to contrasts involving the Larvae or Scolex-Neck (Additional file 2: Table S2.1), suggesting that reproductive growth involves a larger percentage of putatively tapeworm-specific factors than either larval metamorphosis or strobilation.

\section{Gene Ontology}

Gene Ontology (GO) $[46,47]$ terms associated with DE gene models were retrieved from WormBase ParaSite (parasite.wormbase.org; [44, 45]) and used to try and identify differences in term annotations among the samples (GO 'hits' to DE gene models are given in Additional file 2: Tables S2.2-S2.5). In total, 1962 unique terms were 
a Homeobox transcription factors

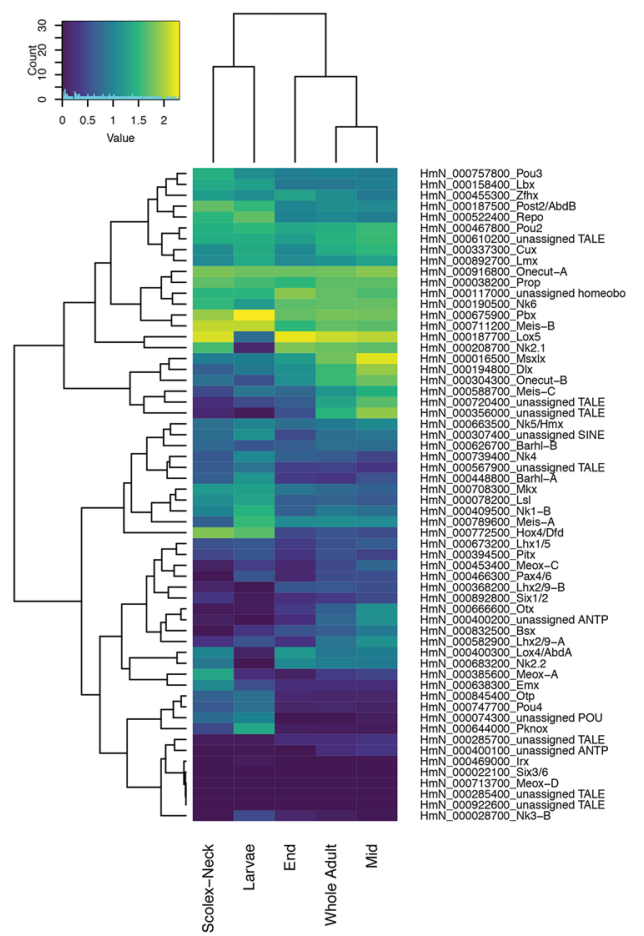

b Wnt, Notch \& Hedgehog signaling components

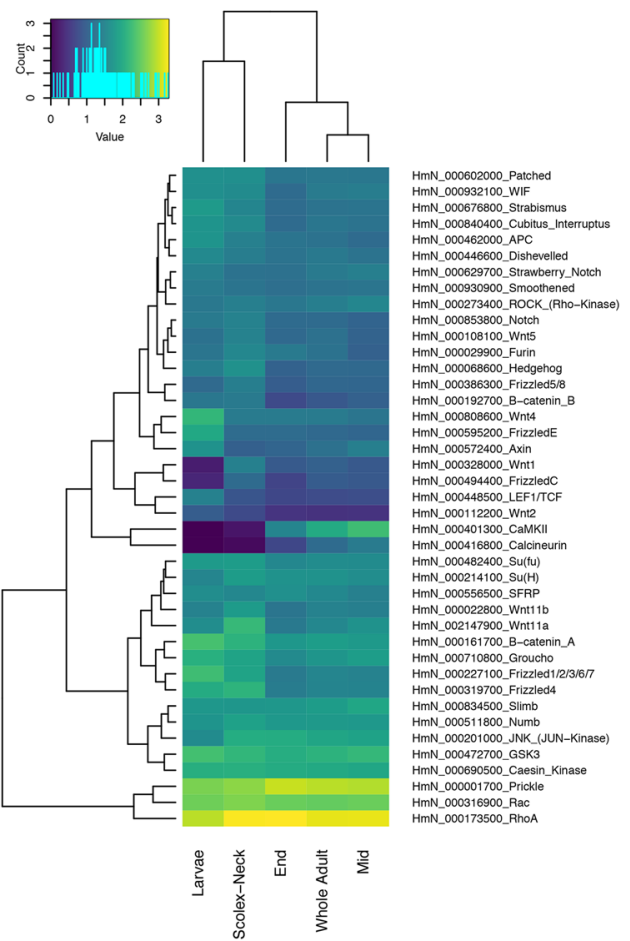

C Differentially expressed genes of interest
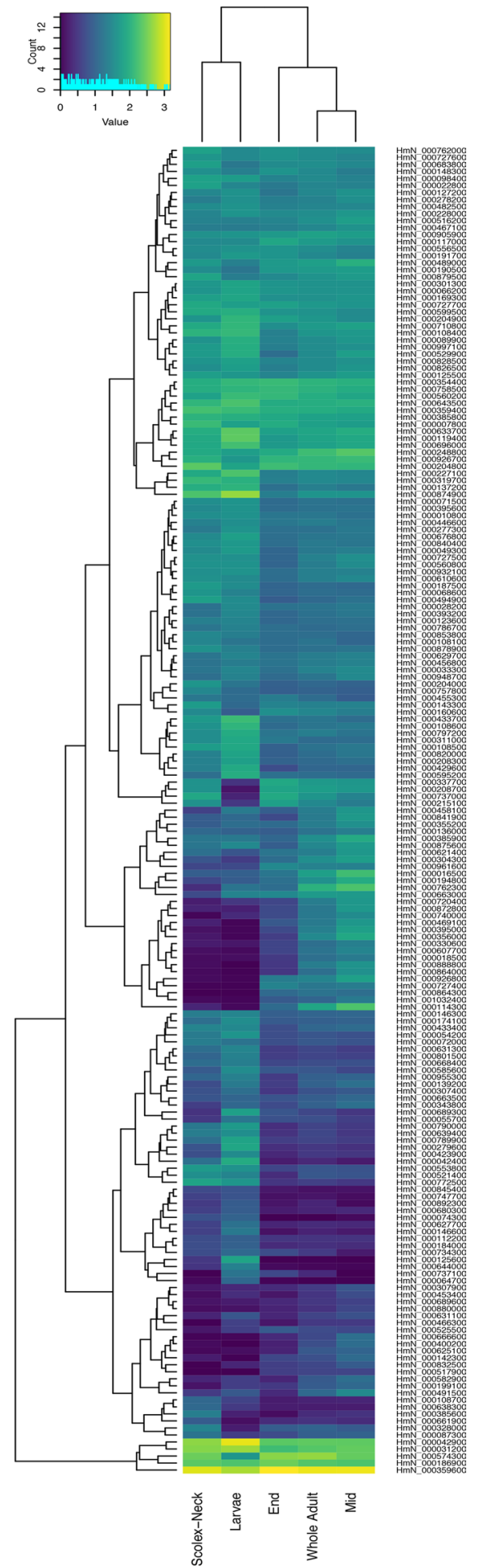

Fig. 2 Heatmaps based on mean, normalised expression of selected factors representing 'signals' and 'switches'. a All homeobox transcription factors [35]. b Wnt, Notch and Hedgehog signalling components [35, 63, 178]. c Differentially expressed genes of interest (Table 2, Additional file 4: Table S4; note that some of the factors in $\mathbf{a}$, $\mathbf{b}$ were differentially expressed in one or more of the contrasts and are therefore also represented in $\mathbf{c}$ ). All three suites of genes produce the same hierarchical clustering of the samples, congruent with that based on overall gene expression (Fig. 1c) 


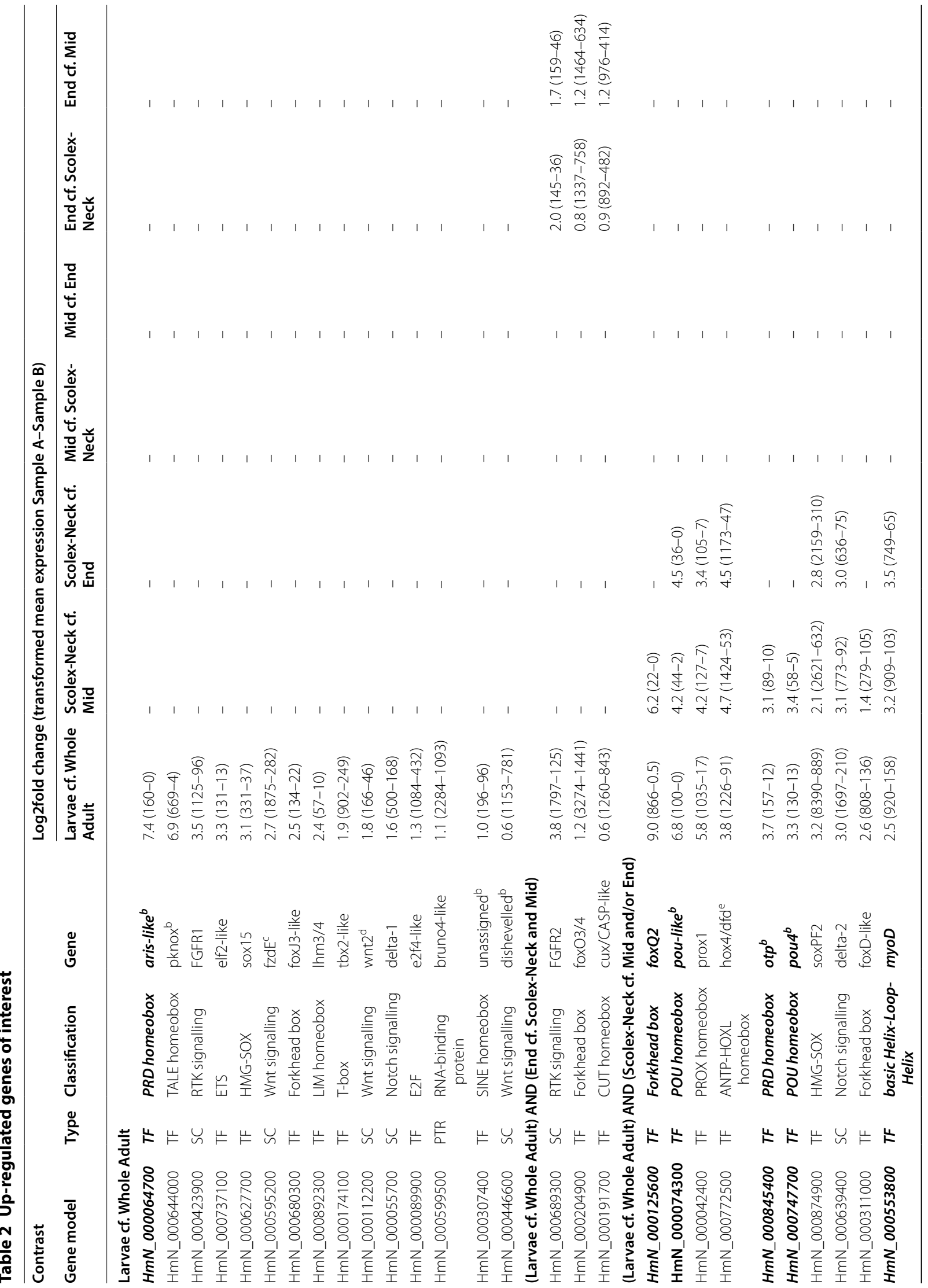




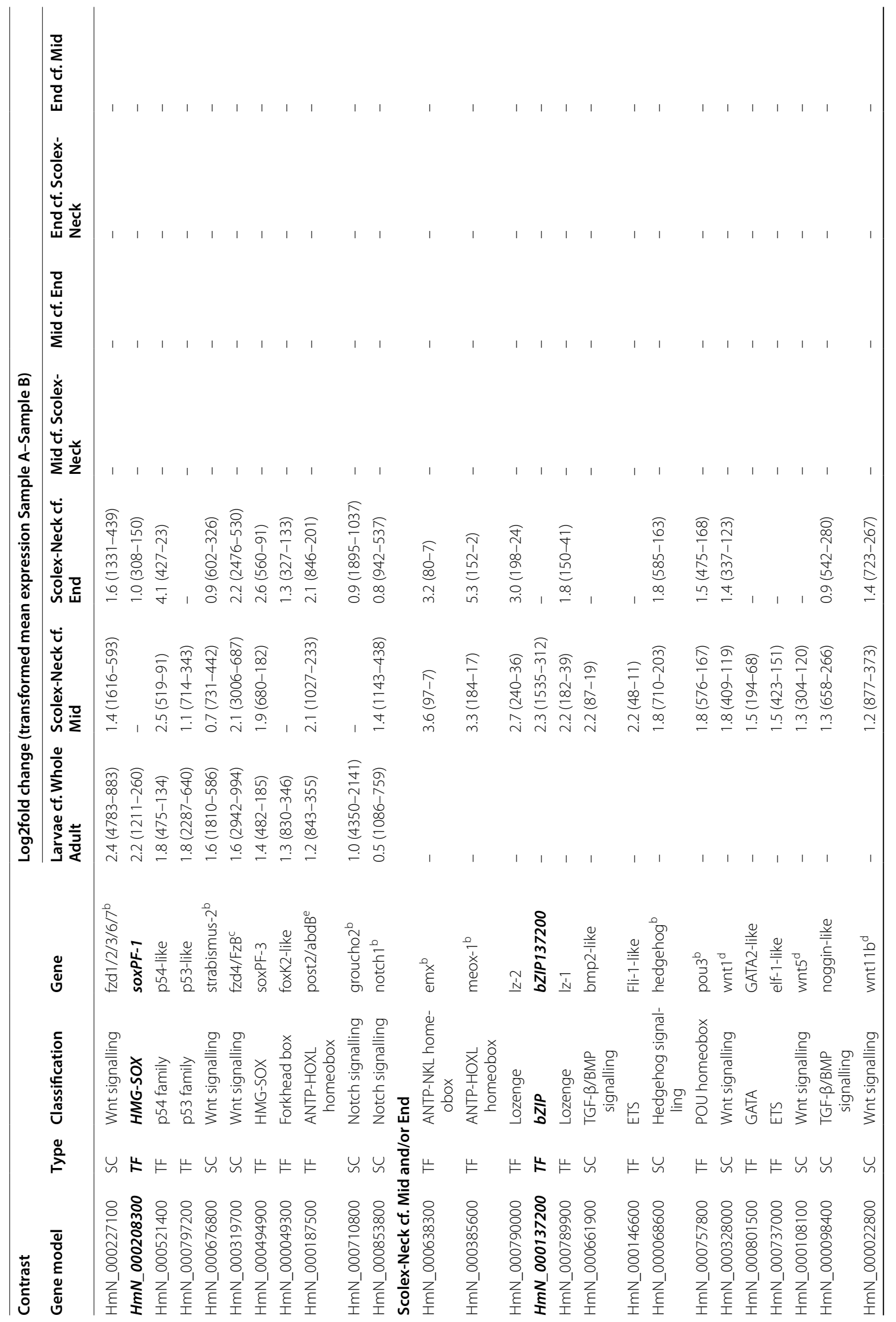




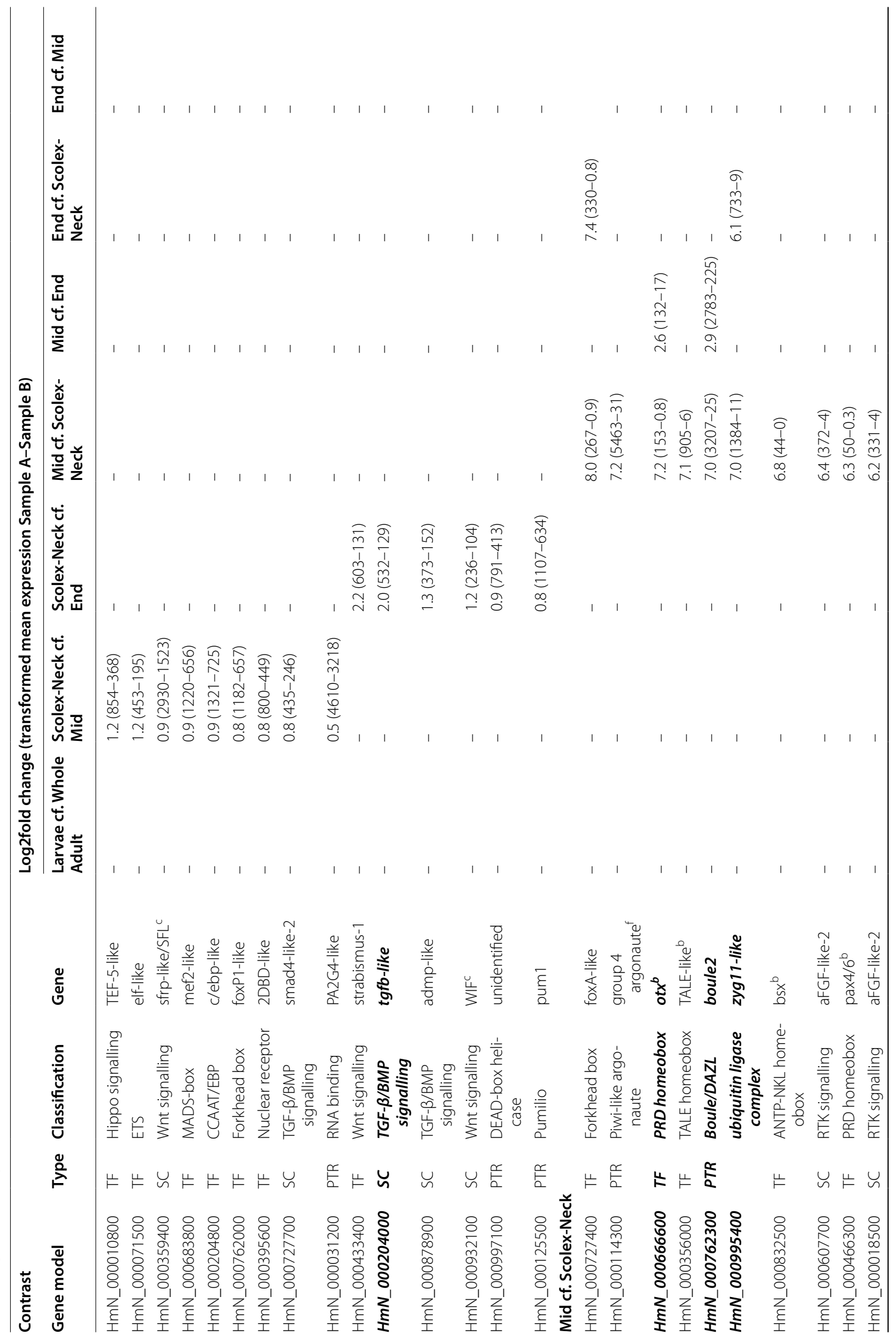




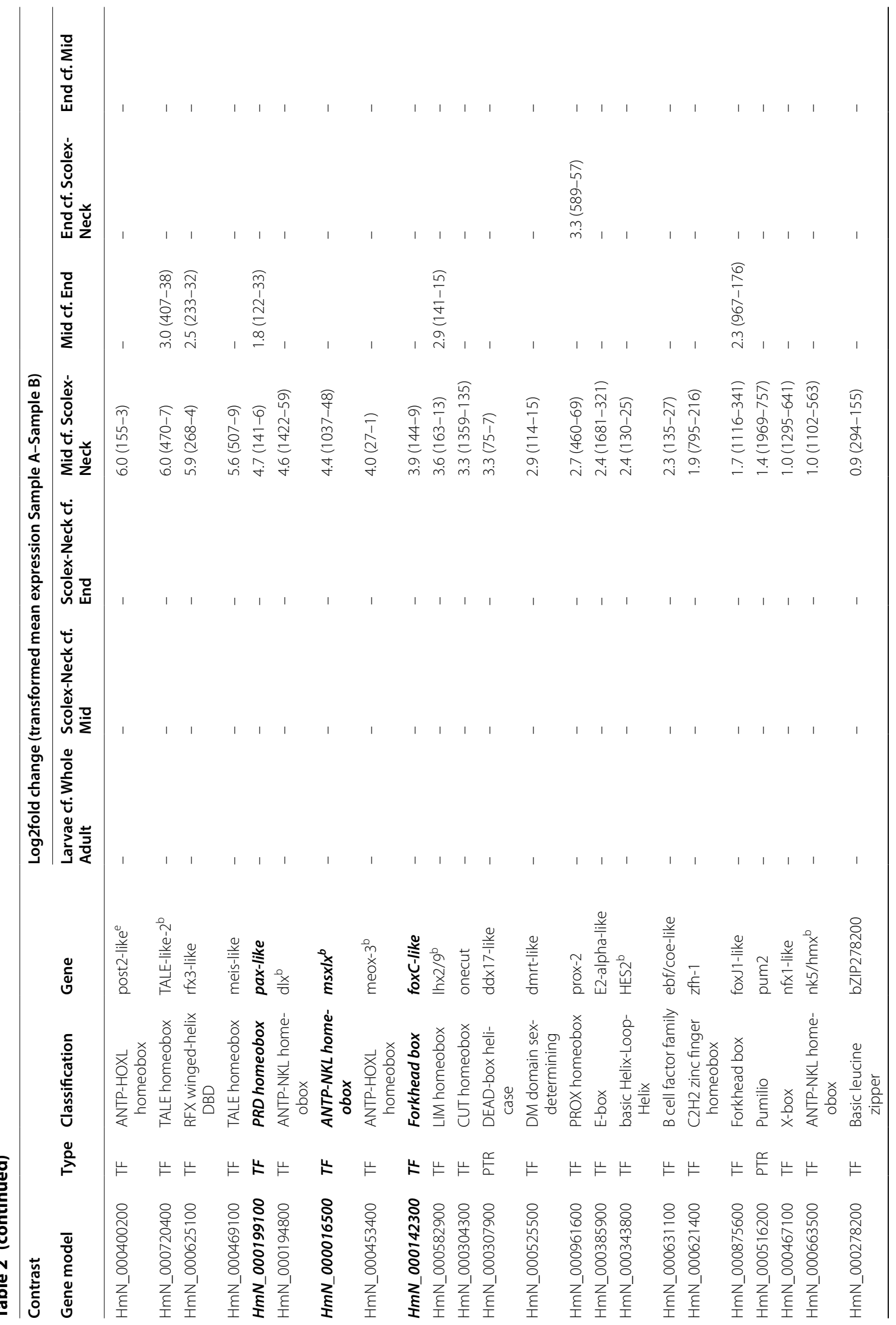


Olson et al. EvoDevo ～(2018) 9:21

Page 11 of 29

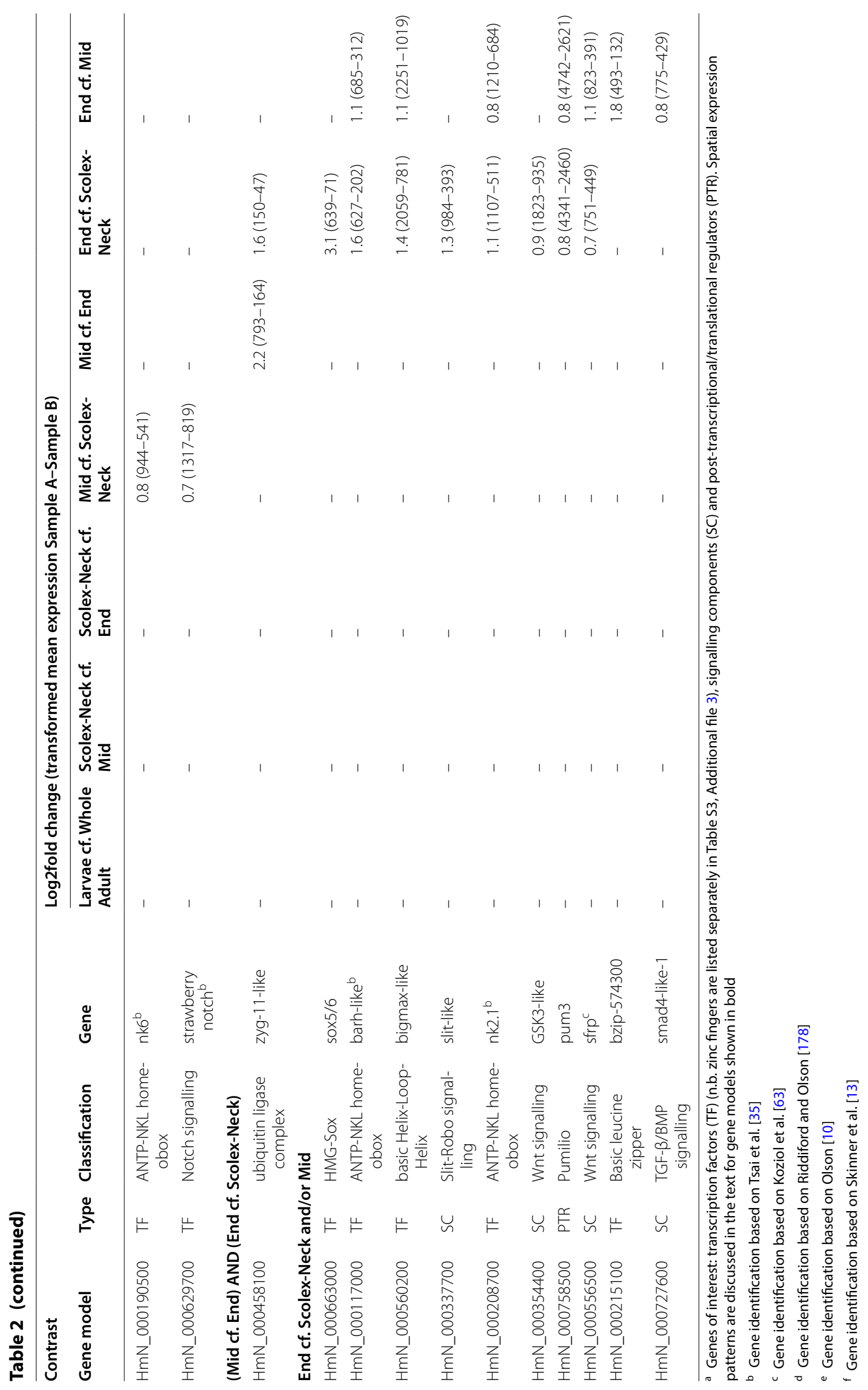


available, 6863 models had at least one annotation, and of these, 4254 models had a biological process annotation. When mapped to higher-level terms (i.e. GO slims), the pattern of annotation between the samples was highly consistent, with metabolic processes being the most represented in all cases (Fig. 3). Notably, despite the overall percentage of models expressed being nearly identical among samples, the Larvae had fewer GO slim annotated hits. Since these GO annotations are generated based on similarity to genes from well-studied organisms (i.e. humans and major model organisms; see Table 2 in [47]), this result suggests that the Larvae are expressing more genes that either have little similarity to other species and remain unannotated, or have annotations to terms that do not fall into the general GO slim categories. For the same reason, we suggest that the overall pattern (Fig. 3) is predominately one that reflects the 'housekeeping' state of the samples and is therefore highly similar, especially among adult samples.

We used GOseq [48] to look for biological process terms that had enriched representation among our sets of DE genes models using all models, and using only those with log2fold-change thresholds of 1.5 or 2.0. However, no biological process category was significant after multiple testing correction at any threshold. We therefore also used REVIGO [49] to reduce the number of terms by removing redundant, related terms. However, even using the 'tiny' option we found that terms were still too numerous for graphical overviews, and thus, we instead present lists of top-level terms for each contrast (Additional file 3: Tables S3.1-S3.7). In many cases, GO provided further support for the putative identities of the GOI, and for zinc finger proteins we used GO annotations to select gene models minimally including both 'metal ion' and 'DNA-templated' binding. Although in principle GO terms could be used to identify models representing major categories of genes, e.g. signalling or transcription, we found that hits against identified GOI were too inconsistent to be used reliably for this purpose. Given this result and the lack of enriched terms in our DE genes, we suggest that the application of this vocabulary to invertebrate, and especially lophotrochozoan, genomes is highly limited.

\section{Genes of interest}

Among the DE gene models with annotations, we identified a total of 189 unique GOI up-regulated in one or more of the contrasts (listed in Table 2 and summarised in Additional file 2: Table S2.1; individual gene models highlighted in Additional file 2: Tables S2.2-S2.5). Forty

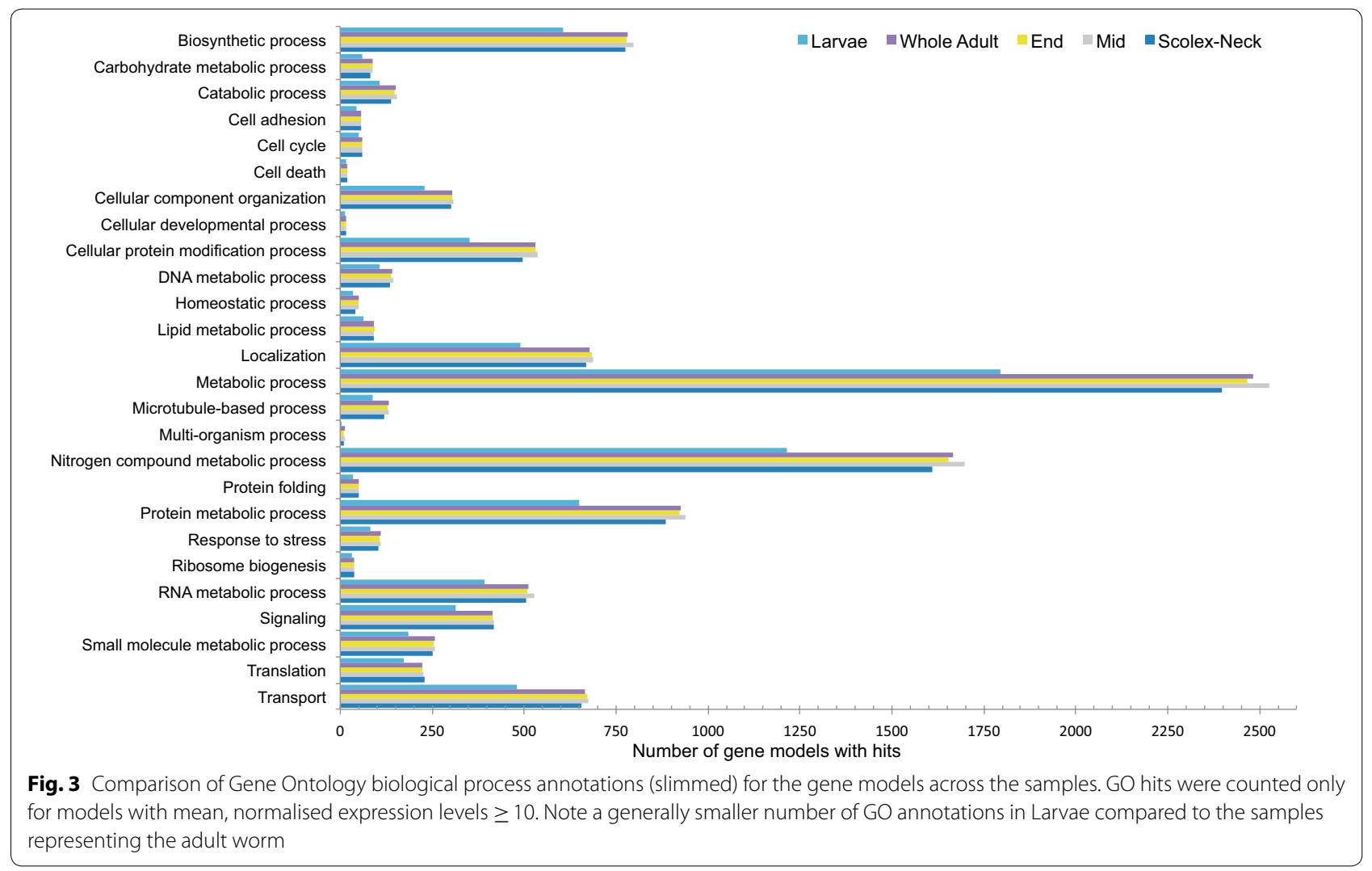


percent of these were putative zinc finger transcription factors, the most abundant class of transcriptional regulators in animal genomes [50], and are compiled separately in Additional file 4: Table S4. The largest number of GOI (and DE genes in general) was identified in Larvae compared to the Whole Adult (Table 1; Additional file 2: Table S2.1), reflecting the coarseness of this contrast relative to those involving samples representing different regions of the adult worm which would be expected to share more similar constitutive (i.e. background) gene expression profiles, and thus a smaller percentage of genes DE. Not considering zinc fingers, 39 GOI were identified in Larvae, more than half of which were also found to be up-regulated in the Scolex-Neck sample when compared to the Mid and/or End samples. Conversely, little overlap in up-regulated GOI was found among other contrasts (Table 2).

Among the regional adult samples, contrasts involving the Scolex-Neck and Mid regions resulted in comparable numbers of GOI (60-61), whereas only $\sim 1 / 3$ as many were identified in the End sample (Table 1). This relative lack of up-regulated GOI could be explained by a loss of power due to the larger variation among replicates of the End sample (Fig. 1b). However, the overall number of DE gene models was comparable or greater in contrasts involving the End sample than in those involving other regions. Similarly, although there was a higher percentage $(\sim 10 \%)$ of novel DE genes in the End sample compared to the Scolex-Neck (and thus fewer annotated gene models from which GOI could be identified), this was equally true for the Mid sample. It therefore seems more likely that the relative lack of GOI identified from the End sample is due to developmental pathways up-regulated in the Mid and/or Scolex-Neck samples also operating in the End sample, and thus not found to be DE. For example, pathways regulating sexual development in the End are likely to be largely the same as those operating in the Mid sample, while pathways regulating some aspects of embryogenesis (e.g. axial patterning) may also be involved in strobilar growth in the Scolex-Neck sample. Thus, although developmental processes such as embryogenesis and senescence are uniquely represented by the End sample, the quantitative approach taken here was limited in its ability to identify associated factors.

\section{Differential expression during larval metamorphosis}

Characteristically, the two most DE transcripts in Larvae were paralogs of the larval-specific tapeworm 'antigen B-like' protein [34] which were massively expressed (24,000 in Larvae cf. 0.5 in Whole Adults; Table S.2.2, Additional file 2). However, among DE GOI, more than half were also found to be up-regulated in the ScolexNeck sample. Those with the highest fold change were the forkhead box gene foxQ2 that was also up-regulated in the Scolex-Neck, followed by an aristaless-like homeobox which was DE only in Larvae. Other zinc finger, homeobox, forkhead box and high mobility group genes comprised the majority of transcription factors DE in Larvae only or in both the Larvae and Scolex-Neck samples. Among signalling components, two FGF receptors were identified, one of which was also up-regulated in the End sample, whereas components of Wnt and Notch pathways were enriched in both the Larvae and Scolex-Neck samples. A total of six Wnt components were identified in Larvae including a Wnt ligand and frizzled receptor DE only in Larvae, and two frizzleds up-regulated in both the Larvae and Scolex-Neck. Similarly, the Notch receptor delta-1 was DE only in Larvae, whereas delta-2 and the ligand notch-1 were DE in both the Larvae and Scolex-Neck. Genes with putative roles in regulating stem cells included the post-translational regulator bruno [51], DE only in Larvae, and members of the p53/54 transcription factor families [52], DE in both the Larvae and Scolex-Neck samples.

Below we discuss spatial gene expression during larval metamorphosis of nine transcripts (Fig. 4), the majority of which were DE in both the Larvae and Scolex-Neck samples (Table 2). Included are two putative zinc finger transcription factors that were not part of those identified in Additional file 4: Table S4, but were previously identified in DE analyses based on an earlier version of the genome.

\section{aristaless}

An aristaless-like Paired-class homeobox was highly DE in Larvae and had a transformed mean of zero in the Whole Adult (Table 2). It is expressed around the developing suckers and rostellum of the scolex, starting as one apical and two bilateral foci that expand and continue to be expressed post-encystment (Fig. 4a). At mid-metamorphosis, expression is broadly consistent with the spatial arrangement of the neurological connections that form together with the principal structures of the scolex (i.e. the apical rostellum and suckers) [39, 53], consistent with a role in the development of the central nervous system (CNS). In vertebrates, the aristaless-related homeobox gene $A R X$ plays a pivotal role in neurogenesis and dysregulation is implicated in multiple neurological disorders [54], whereas it is involved in distal appendage formation in insects [55-57] and tentacle formation in Hydra [58]. Paired genes represent the second most diverse class of homeoboxes after ANTP [59], and many Paired-family genes are expressed in the nervous system of animals (e.g. otp, discussed below), including lophotrochozoans [60]. 

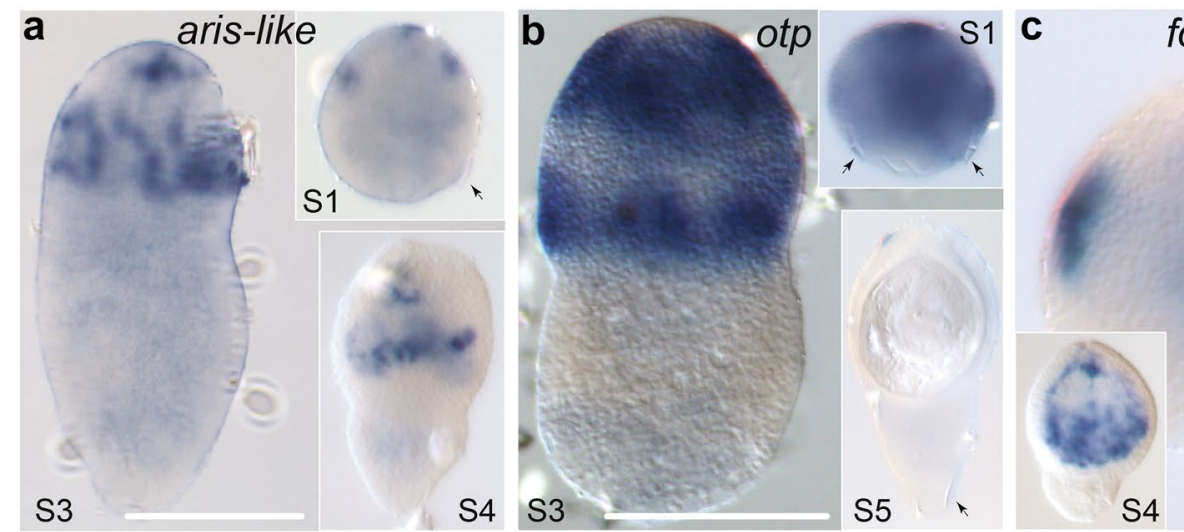

foxQ2
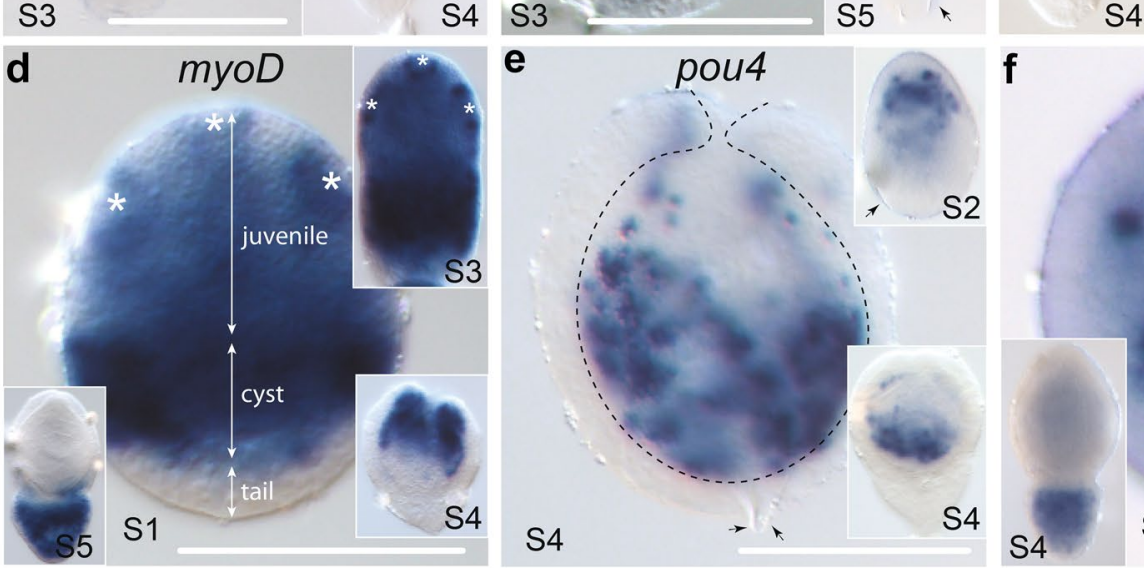

S1
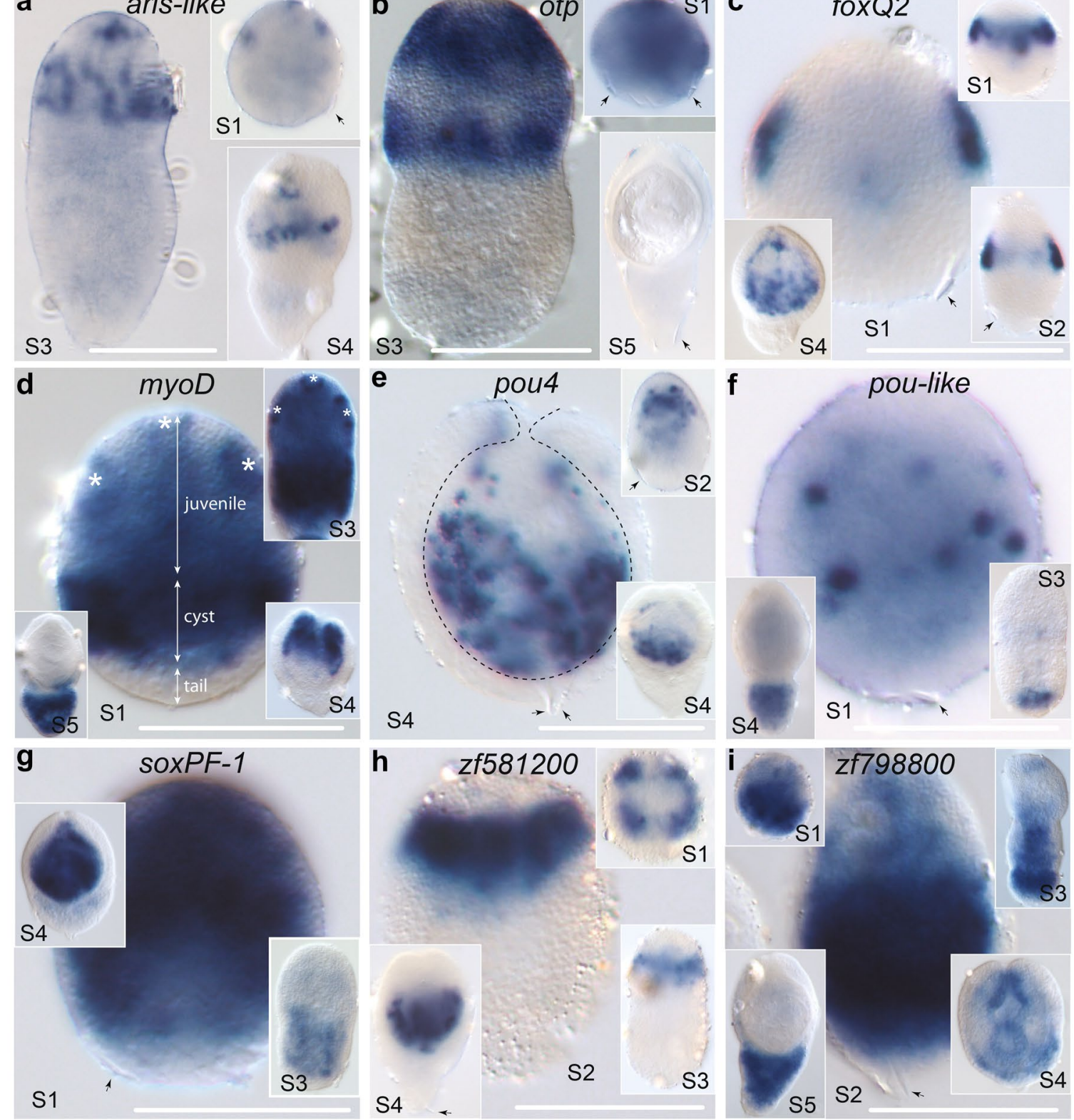

Fig. 4 Spatial gene expression during larval metamorphosis. Larvae are staged as shown in Fig. 1a. Asterisks in d the nascent suckers and rostellar bulb, and arrows indicate the regions of the Larvae that give rise to the juvenile worm, cyst tissues and tail. Dotted line in e the boundary between the encysted juvenile worm and surrounding tissues. Arrows show oncospheral hooks where visible, indicating the larval posterior [63]. Gene models: aris-like (HmN_000064700), foxQ2 (HmN_000125600), myoD (HmN_000553800), otp (HmN_000845400), pou4 (HmN_000747700), pou-like (HmN_000074300), soxPF-1 (HmN_000208300), zf581200 (HmN_000581200), zf798800 (HmN_000798800). All scale bars 50 um

\section{orthopedia}

A putatively CNS-related pattern of expression is also seen in an ortholog of the Paired-class homeobox orthopedia $(\mathrm{Otp})$. Hmic-otp expression is diffuse in early-stage Larvae, but by mid-metamorphosis is restricted to the anterior hemisphere that gives rise to the juvenile worm. There it is expressed in large foci that overlap and encircle the Larvae in two 'stripes', one sub-apical and the other reaching the equator (Fig. 4b). Otp is a canonical regulator of brain development in animals [61], including 
planarians in which it is expressed in the outer branches of the brain during homoeostasis and in an apical patch in head blastemas during regeneration [62]. Although the expression pattern of Hmic-otp is more dispersed than that of Hmic-aris, it is broadly consistent with the areas where the cerebral ganglia and innervation of the suckers and rostellum.

\section{foxQ2}

An ortholog of foxQ2 is expressed in bilateral foci at the sides of the larva during the initial phase of metamorphosis and post-encystment becomes dispersed around the suckers (Fig. 4c). This is similar to the pattern seen in developing protoscoleces of the fox tapeworm Echinococcus multilocularis [63] and consistent with the patterning of the main branches of the CNS and innervation of the scolex. FoxQ2 is a key regulator in the earliest stages of anterior patterning in animal embryos and in the development of the CNS [64-67]. As in tapeworms, foxQ2 is not expressed apically in planarians, but in various parts of the nervous system, including photoreceptor neurons [68] and neural progenitor cells [69]. FoxQ2 is also upregulated in the Scolex-Neck sample, albeit at levels that are orders of magnitude less than in Larvae (Table 2), whereas no read mapped to this gene model in the Mid and End samples (Additional file 1: Table S1.2).

\section{myoD}

Neurogenesis occurs in concert with muscle development, and in both the Larvae and Scolex-Neck samples we find strong up-regulation of a $m y o D$ ortholog, a universal regulator of myogenesis in animals [70]. WMISH shows clear spatial and temporal changes throughout metamorphosis, and the three regions of the nascent cysticercoid larva are readily demarcated by its expression (Fig. 4d). The anterior hemisphere shows diffuse expression throughout, whereas more concentrated expression makes visible the nascent suckers and rostellar bulb (marked by asterisks). The posterior hemisphere shows a strong band of expression in the cyst tissues around the 'primary lacuna' (i.e. larval cavity) in which thin sheets of muscle develop. Meanwhile, cells posterior to the cyst region that will subsequently form the 'tail' show no expression during early stages of metamorphosis. HmicmyoD continues to be expressed strongly in the developing juvenile post-encystment (S4) and becomes restricted to the tail in the mature cysticercoid (Fig. 4d).

$M y o D$ is a basic helix-loop-helix (bHLH) type transcription factor that has been described as a 'master switch' capable of inducing and orchestrating the differentiation of skeletal muscle cells in vertebrates [71]. Muscle development has been well described in planarians [72-74], and a myoD ortholog is expressed in both putative myogeneic progenitor cells [69] as well as fully differentiated myocytes [74]. More recently, Scimone et al. [75] showed that Smed-myoD does not play a generalised role in planarian muscle development, but is instead specific to the formation of a single muscle layer: the longitudinal muscles. Selectively inhibiting their formation via RNA interference revealed that the different muscle layers play distinct instructive roles during regeneration [75]. MyoD expression in Hymenolepis shows patterns consistent with the development of its larval muscle architecture, but further work is required to test whether its expression is specific to a particular layer.

\section{pou4 and pou-like}

Two POU-class homeoboxes show scattered, punctate expression. Spatial expression of pou4 is restricted to the anterior, juvenile-forming half of the larva, with increased expression following encystment (Fig. 4e). Pou-like shows fewer foci more equatorially distributed during early metamorphosis, becoming diffuse and restricted to the posterior tail of the Larvae post-encystment (Fig. 4f). POU-class genes are found in all animals and are characterised by possession of separate POU and homeobox DNA-binding domains tethered by a variable linker region [76]. Parasitic flatworms possess orthologs of POU2, POU3, POU4 and POU6 family genes together with a single 'orphan' POU-like gene [35]. They have thus lost members of the POU1 family hypothesised to be present in the ancestor of the Lophotrochozoa, whereas the POU5 class is novel to vertebrates [77]. POU genes are involved extensively in nervous system development and in the regulation of stem cell pluripotency in vertebrates [76, 78, 79], and CNS-related expression has been shown in a range of lophotrochozoans, including planarians [80] and octopi [81]. POU genes are enriched in planarian neoblasts [82], and Scimone et al. [83] demonstrated the role of a pou $2 / 3$ gene (putatively orthologous to pou 3 orthologs in parasitic flatworms [35]) in the development of the planarian's protonephridial system. Restriction of Hmic-pou4 to the areas of the developing scolex combined with conserved roles of POU genes in neurogenesis is consistent with its involvement in CNS development, like aris, otp and foxQ2. In contrast, the posterior, cystrestricted expression of the 'orphan' pou-like gene makes it unlikely to be involved in either CNS or protonephridial development.

soxPF-1

A Sox (SYR-like box) family transcription factor is expressed in a diffuse and dynamic fashion, appearing ubiquitous in S1 Larvae save the most posterior region, then seen in the nascent cyst tissues in S3, and finally restricted to the developing juvenile post-encystment (S4; 
Fig. 4g). SoxPF-1 is one of three paralogs that are part of a parasitic flatworm-specific expansion of Sox genes, all of which show up-regulation in both the Larvae and ScolexNeck samples (Table 2). In planarians, the Schmidtea soxP1 gene and the presumably paralogous genes SmedsoxP2 and Smed-soxP3 are all expressed in neoblasts, but only soxP1 is required for their long-term maintenance [84]. Sox genes are canonical regulators of metazoan stem cells capable of reprogramming differentiated cells $[85,86]$. Spatial expression of soxPF-1 in Hymenolepis may reflect cell proliferation during the different phases of metamorphosis, such as the formation of the cyst tissues and morphogenesis of the juvenile worm, and if so would be consistent with the gene product having a canonical role in regulating stem cells, as they comprise the only proliferative cell compartment in flatworms [27].

\section{zf581200 and $z f 798800$}

Two unclassified, C2H2-type zinc finger transcription factors show strong expression in Larvae: $z f 581200$ is expressed in a quartet pattern in the anterior of the Larvae, prefiguring development of the suckers (Fig. 4h), while $z f 798800$ exhibits diffuse expression that becomes restricted posteriorly through the course of metamorphosis (Fig. 4i). In the present analyses, zf581200 shows only 2 fragments mapped to Larvae (Additional file 1 : Table S1.2), whereas gene model HmN_000798800 is not supported in the v. 2 assembly, albeit our empirical data show that it represents a bona fide gene transcript. At least 37 types of specific binding domains characterise the zinc finger super-family, of which the $\mathrm{C} 2 \mathrm{H} 2$ type is the most abundant $[87,88]$ and there are nearly 200 zinc finger genes in the $H$. microstoma genome [35]. It is hypothesised that lineage-specific expansion of transcription factors such as these plays a role in the changes in gene regulatory networks that produce unique traits in animals $[88,89]$, and thus, although almost all of the putative zinc fingers identified are unclassified (Additional file 4: Table S4), their spatial expression patterns would be nevertheless valuable to survey.

\section{Differential expression in the Scolex-Neck region}

Differentially expressed GOI in the Scolex-Neck contrasts included a wide diversity of major types of transcription factors and more signalling components (18) than were found among the other contrasts. As previously discussed, nearly half of the GOI up-regulated in Scolex-Neck cf. Mid and/or End samples (35 of 77) were also up-regulated in the Larvae sample (Table 2 and Additional file 4: Table S4). Components of Wnt signalling included two Wnt ligands (wnt1 and wnt11b) and repressors (sfrp-like and wif) and a paralog of strabismus, DE only in the Scolex-Neck, in addition to another strabismus paralog and two frizzled receptors $\mathrm{DE}$ in both the Scolex-Neck and Larvae. Notch signalling components, including orthologs of a Notch ligand and a Delta receptor, were also up-regulated in both the Scolex-Neck and Larvae samples, as noted above. Unlike the Larvae, however, DE GOI in the Scolex-Neck also included five components of TGF- $\beta / \mathrm{BMP}$ signalling, including tgf $b$ and bmp2-like genes, an ortholog of Hedgehog, the primary ligand of the Hedgehog signalling pathway, and a tef-5like transcript associated with Hippo signalling [90, 91]. One of three paralogs of the stem cell regulator Pumilio $[92,93]$ (pum1) is up-regulated relative to the End sample (but not to the Mid), whereas the remaining paralogs, pum 2 and pum3, are independently up-regulated in the Mid and End samples, respectively (Table 2).

Below we discuss spatial expression patterns in the Scolex-Neck and immature strobila of five genes:

\section{snail}

An ortholog of snail is expressed in a gradient around the medullary region and fades after the transition with the strobila (Fig. 5a). Further down the strobila, it is weakly expressed in the genital primordia (Fig. 5f). Here the gene model was not found to be DE but had been previously identified as such when the RNA-seq data were mapped to an earlier version of the genome assembly. Snail is a C2H2-type zinc finger transcription factor [94] encoding a protein that negatively regulates binding of $m y o D$ in progenitor myoblasts in mice, controlling their transcriptional state from one of proliferation to differentiation [95]. In Schmidtea, a direct ortholog of Hmicsnail is expressed together with Smed-myoD in a distinct population of muscle-related progenitor neoblasts [69]. Myogenesis in the neck is clearly required for the continual extension of the body by intercalation of new muscle cells. If snail plays a canonical role in tapeworms, then neoblast specialisation in planarians suggests that its expression pattern most likely represents a sub-population of germinative cells with a myogenic fate. Moreover, it would follow that what appears to be a lack of expression in the cortical (outer) region would be explained by migrating myogenic cells transitioning from a state of proliferation to one of differentiation [95].

\section{bZIP137200}

An unclassified, basic-region leucine zipper (bZIP) transcription factor exhibits intense, diffuse expression in the neck that fades in a gradient at the transition with the strobila (Fig. 5b), as well as secondary foci of expression in the nascent seminal receptacle (Fig. 5g). Like bHLH transcription factors, bZIP proteins dimerise to form DNA-binding motifs and predate the origin of Metazoa [96]. The repertoire of bZIP class genes is largely 


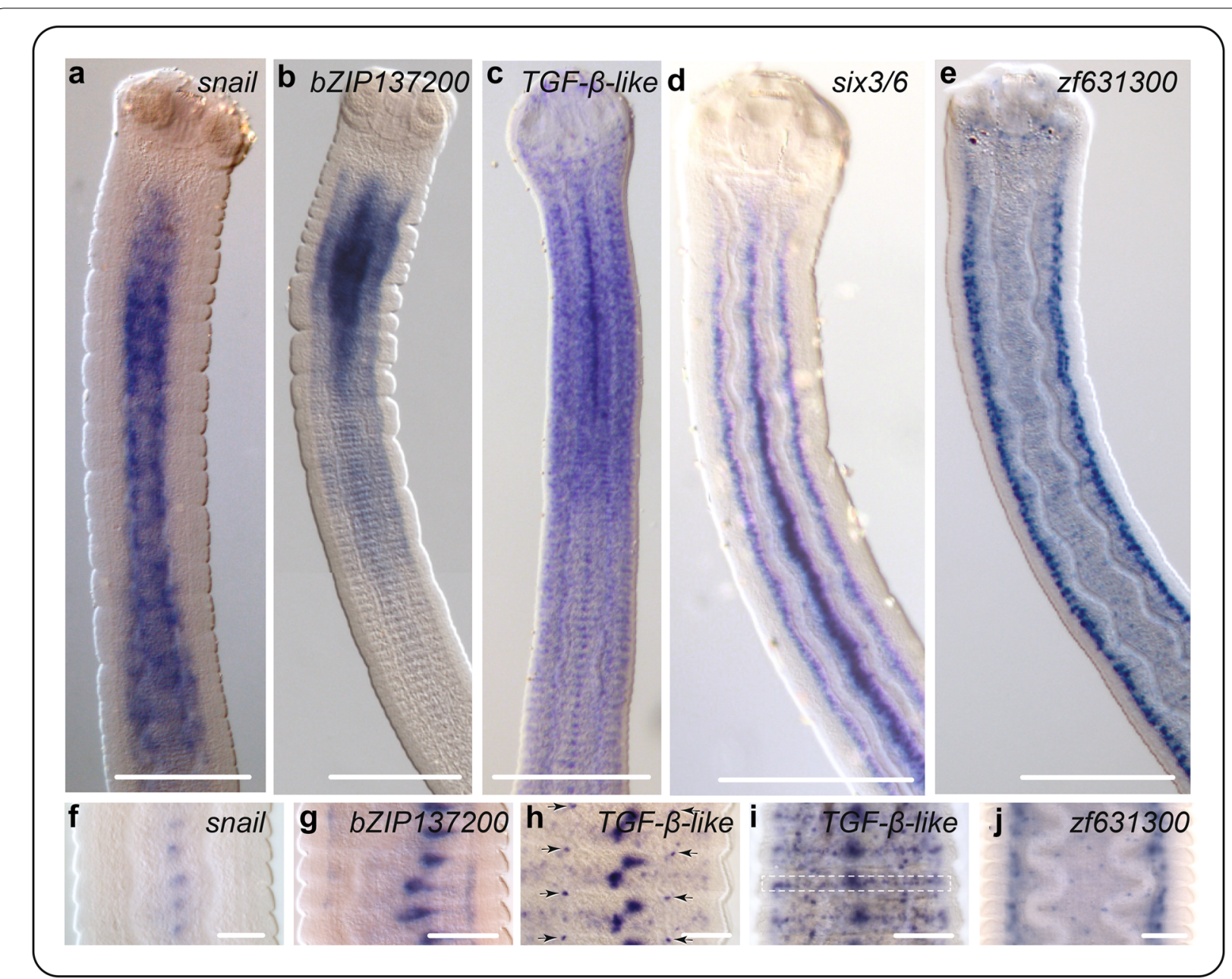

Fig. 5 Spatial gene expression in the Scolex-Neck. a-d Expression in the scolex, neck and immature strobila. $\mathbf{f}$ Expression of snail in the genital primordia. $\mathbf{g}$ Expression of bZIP137200 in the nascent seminal receptacle. $\mathbf{h}, \mathbf{i}$ Expression of tgfb-like in immature segments. Arrows in $\mathbf{h}$ segmental, dorsoventrally paired foci, and dotted box in i punctate stripe of expression across the segments, both patterns consistent with the positions of segmentally repeated elements of the nervous system [39]. $\mathbf{j}$ Expression of zf631300 showing punctate expression in the cortex. Gene models: bZIP137200 (HmN_000137200), six3/6 (HmN_000022100), snail (HmN_000348000), tgfb-like (HmN_000204000), zf631300 (HmN_000631300). Scale bars $200 \mu \mathrm{m}(\mathbf{a}-\mathbf{e}), 50 \mu \mathrm{m}(\mathbf{f}-\mathbf{j})$

unknown outside of major animal and plant models, especially in regard to lophotrochozoan taxa. However, a total of 29 bZIP genes were identified among the gene models of the Japanese oyster [97], including putative orthologs of many genes found in ecdysozoans and deuterostomes. The restricted expression of bZIP137200 in the neck region and in the nascent reproductive organs points towards a role in a proliferative $(=$ stem $)$ cell compartment.

The patterns of both snail and bZIP137200 appear to involve expression near the boundary of the medullary and cortical regions where there is a confluence of primary nerve elements, thick longitudinal muscle bundles and germinative cells $[37,39,53]$. Signalling between the nerve-muscle system and neoblasts is central to the developmental regulatory networks of planarians [98, 99], suggesting that this boundary in tapeworms represents a putative 'signalling cylinder' found not only the neck region, but extending the length of the strobila [12, 100]. As transcription factors act as up-stream or downstream elements in signalling pathways, those DE in the Scolex-Neck are likely to be linked to developmental processes specific to the region.

\section{TGF- $\beta$-like}

A TGF- $\beta$-like ortholog is expressed in multiple foci throughout the worm. In the neck, it is expressed in the genital primordia (misnamed the 'primitive streak' in 
tapeworms) and in a dense, punctate pattern that extends into the scolex (Fig. 5c). Beyond the neck a more regular, segmental pattern emerges that includes a central foci of expression representing the genital primorida that can be seen later to split antero-posteriorly (Fig. 5h) into the putative anlagen of the seminal vesicle/vagina and the ovary/vitellarium, or alternatively as a split between the male and female systems, as described in the rat tapeworm Hymenolepis diminuta by Sulgatowska [101]). Also visible is a quartet of dorsoventrally paired foci at the inter-segmental boundaries (Fig. 4h) corresponding in position to the junction of the medial longitudinal and traverse nerve cords, suggesting that these may act as centres of inter-segmental signalling. Finally, we observe a 'stripe' of expressing cells that circumscribes each segment at their equator (Fig. 5i).

TGF- $\beta$-like orthologs encode ligands of the highly conserved metazoan TGF- $\beta$ /BMP signalling pathway and are involved in a wide range of morphogenic processes, often with pleiotropic effects [102, 103]. Ligands of TGF- $\beta /$ BMP signalling fall into two broad superfamilies that stimulate different intracellular transducers (Smad proteins) resulting in the transcriptional regulation of different target genes. A direct ortholog of Hmic-tgfb-like in the bloodfluke Schistosoma mansoni (Add. File 1) was shown by Freitas et al. [104] to be expressed in the ovary and vitellaria of female worms (and sub-tegumentally in association with the oral and ventral suckers of males) and was deduced to have a role in embryogenesis. In Hymenolepis, we also see expression in the female system as well as many additional foci, suggesting multiple roles of TGF- $\beta$ signalling throughout tapeworm development.

Using data from the $S$. mansoni genome [32] to represent flatworms, Kenny et al. [105] identified a total of five type I/II receptors and five Smads, but found only two TGF- $\beta$-type genes and no BMP-type gene. The large number of receptors relative to ligands suggested that some of the $S$. mansoni receptors may be responding to host ligands [106]. However, using the latest assemblies of the S. mansoni genome [33] on WBP we do find both TGF- $\beta$ - and BMP-type orthologs in all major groups of parasitic flatworms, as well as in planarians. Moreover, a bmp2-like ligand is up-regulated in the Scolex-Neck (Table 2), but its spatial expression was not examined. The roles of TGF- $\beta$ signalling via Smad $2 / 3$ in flatworms have not been identified, whereas the highly conserved role of BMP signalling in dorsoventral patterning of animals [107] has been well studied in planarians in which it is involved in both dorsoventral and midline patterning [108-113], and we would expect to find the same in other flatworms.

\section{six3/6}

An ortholog of the sine oculus/Six homeobox family six3/6 is expressed in three vertical 'stripes' in the neck and anterior strobila. Expression begins immediately following the scolex and runs along the dorsoventral midline just to the sides of the osmoregulatory canals and in the central 'primitive streak' (Fig. 5d). Posteriorly, expression becomes more punctate in the immature region of the strobila and then fades. Six $3 / 6$ family genes, like foxQ2, are canonical regulators of anterior neural patterning during embryonic development [114, $115]$, and more generally, of early head patterning in animals $[65,116]$. An Echinococcus multilocularis six $3 / 6$ ortholog is expressed in protoscolices in the area of the rostellar nerve ring, the most apical region of the tapeworm CNS $[63,117]$. In planarians, it is expressed in the outer cephalic branches of the brain [118] and in neural progenitor neoblasts [69]. Its spatial expression during strobilar growth in Hymenolepis is associated with the main longitudinal nerve cords, consistent with having a canonical role in the development and/or maintenance of the nervous system during strobilation and early stages of segment maturation, whereas expression in the genital primordia indicates an additional role in proglottid development. Like snail discussed above, six3/6 was previously identified as DE in the Scolex-Neck and our empirical data corroborate this. However, only a few RNA-seq reads mapped against this gene model in the v.2 assembly (Additional file 1: Table S1.2).

\section{zf631300}

Zf631300 is an unclassified C2H2-type zinc finger DE in both the Larvae and Scolex-Neck (Additional file 4: Table S4) that in adults shows strong expression in association with the main elements of the CNS (Fig. 5e), as well as more dispersed, punctate expression in the tissues of the strobila (Fig. 5j). Expression associated with the nervous system is tightly clustered around the main longitudinal nerve cords and cerebrial ganglia in the scolex, appearing as individual foci ('dots') of expression surrounding the main nerve cords. One possibility is that this pattern represents expression by the nerves themselves which have been shown to be distinctly vesicular in tapeworms [53,119, 120], suggesting that the CNS may act as a neurocrine organ $[120,121]$.

\section{Differential expression in the mature strobila}

GOI in the Mid sample were dominated by transcription factors (Table 2; Additional file 3: Table S3), which made up $90 \%$ of the 59 GOI DE relative to the Scolex-Neck. Although zinc fingers were the most abundant type of transcription factor, as in all contrasts, homeoboxes made up a larger percentage of the total GOI in the Mid sample 
(28\%) than in any other contrast, and included members of the HOXL, NKL, PRD, TALE, LIM, CUT and PROX families (Table 2; homeoboxes classified in S10.1 in [35]). The GOI with the highest fold change, however, was a forkhead box transcription factor, foxA-like. The only DE signalling components identified were two aFGF-like receptors, while two up-regulated transcription factors, strawberry notch and a member of the Hes (hairy and enhancer of split) family, are linked to Notch signalling [122]. Other GOI were post-transcriptional regulators that had among the highest transformed expression levels, including some whose products have canonical roles in stem cell regulation: a Piwi-like argonaute [13], the meiosis regulator Boule (discussed below), and one of three orthologs of Pumilio, noted above. Below we discuss the spatial expression of ten genes in the mature strobila, all of which proved to be associated with the female and/or male reproductive systems, and in multiple instances showed a second focus of expression consistent with the innervation of the genital pores.

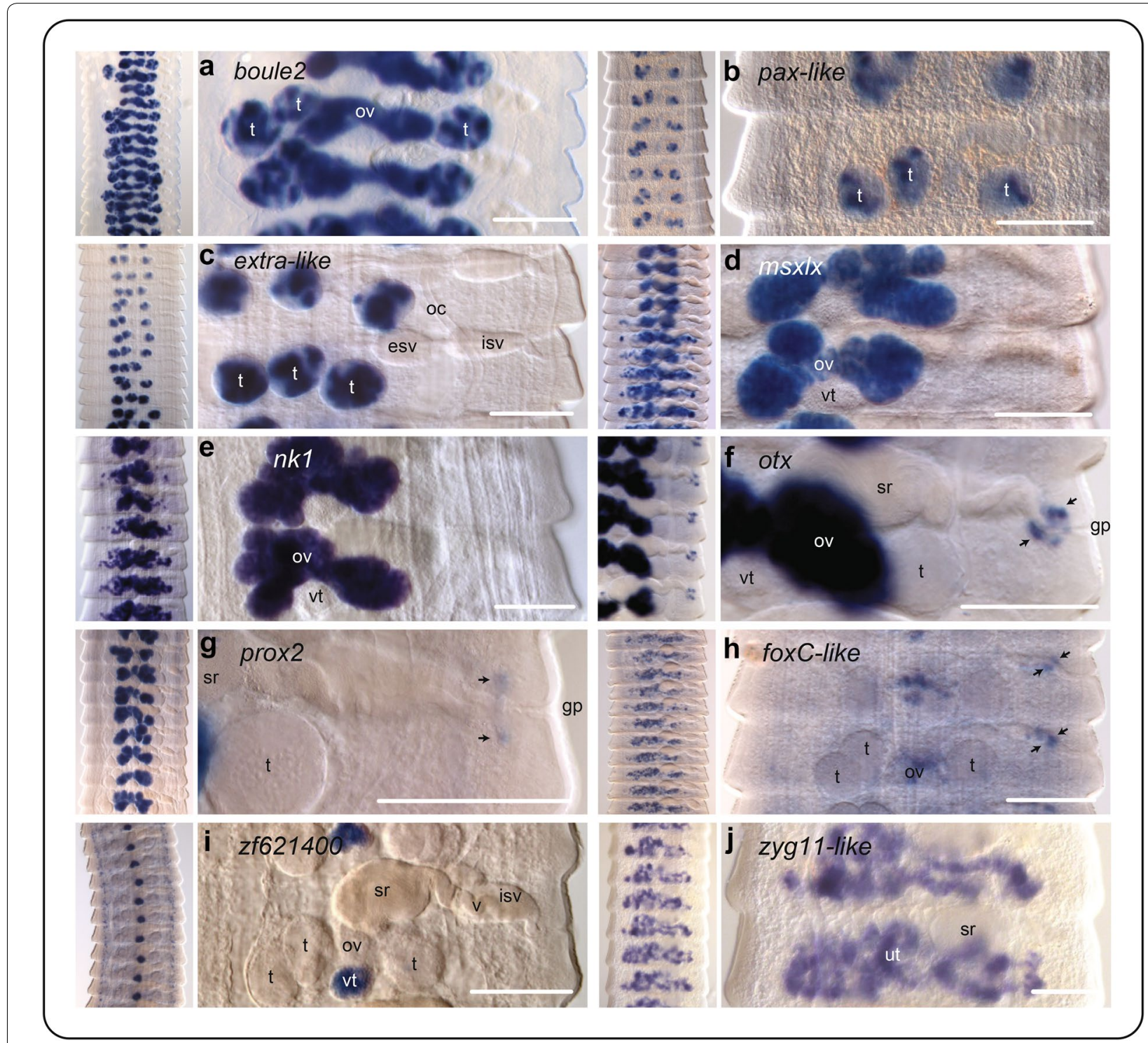

Fig. 6 Spatial gene expression in the mature strobila. Arrows in $\mathbf{f}-\mathbf{h}$ indicate expression foci around the genital pore. esc external seminal vesicle, gp genital pore, esv external seminal vesicle, isv internal seminal vesicle, oc osmoregulatory canal, ov ovary, sr seminal receptacle, $t$ testes, ut uterus, $\checkmark$ vagina, vt vitellarium. Gene models: boule (HmN_000762300), extra-like (HmN_000610200), foxC-like (HmN_000142300), msxlx (HmN_000016500), nk1 (HmN_000601100), otx (HmN_000666600), pax-like (HmN_000199100), prox2 (HmN_000961900), zf621400 (HmN_000621400), zyg11-like (HmN_000995400). All scale bars $100 \mu \mathrm{m}$ 


\section{boule2}

An ortholog of the Boule/DAZL-family RNA regulator boule is strongly up-regulated in both the testes and ovaries (Fig. 6a). Boule 2 encodes an RNA-binding protein essential to germline development [51] and has been shown to regulate meiosis throughout the Cnidaria + Bilateria [123]. Boule expression in animals is generally male specific [123] but is associated with both the male and female germlines in flatworms, consistent with the expression foci seen in $H$. microstoma. The freeliving flatworm Macrostomum lignano has three copies of boule, two of which are associated with the testes (one involved directly in spermiogenesis) and one with oogenesis in the ovaries [124]. In Schmidtea, there are also two paralogs, both of which are involved in spermatogenesis and oogenesis: Iyer et al. [125] showed that Smed-boule1 has a canonical role in the regulation of meiosis, whereas Smed-boule2 has a pre-meiotic role in the maintenance of early male germ cells, analogous but not homologous to the role played by DAZL genes in vertebrates. In the same year, Steiner et al. [126] showed that a Schmidtea boule ortholog (=Smed-boule2 in [125]) is required for both male and female gamete production, but that whereas Smed-boule2(RNAi) results in sterility, it does not inhibit the production of egg capsules. Gene trees generated via WBP (not shown) indicate that a majority of parasitic flatworms have two paralogous BouleDAZL-type genes that form separate clades, one of which includes Smed-boule1 and Smed-boule2, whereas the other clade appears to be specific to neodermatans and includes the Hmic-boule 2 paralog analysed here.

\section{pax-like and extra-like}

Testes-specific, regionalised expression was seen in a pax-like PRD-class gene (Fig. 6b) and an unclassified extradenticle-like TALE-class gene (Fig. 6c). Pax genes have been shown to regulate cell lineage specification and maintain progenitor cell populations through alternative splicing and gene activation/repression [127], and in mammals pax7 expression is also specific to the male germline [128]. BLAST identification of the TALE-class gene returns extradenticle as the best match, but gene trees (not shown) suggest that it is one of at least eight unassignable genes that are part of a TALE-class expansion specific to parasitic flatworms [35]. Moreover, it is not orthologous to planarian $P B X /$ extradenticle which is involved in anteroposterior (AP) polarity during regeneration by affecting Wnt signalling [129]. While there is scarcely information on the roles of these genes in invertebrates, spatial expression in Hymenolepis demonstrates their involvement in the male reproductive system.

\section{$m s x l x$ and $n k 1$}

Spatial expression of other up-regulated genes examined from the Mid sample was specific to the female system. Two ANTP-type homeoboxes, $m s x l x$ and $n k 1$, are strongly up-regulated in the ovaries and continue to show expression in fertilised ova in the uterus (Fig. 6d, e). $M s x / m s h$ genes encode conserved proteins that act as transcriptional repressors involved in cell proliferation, differentiation and organogenesis during embryonic development [130]. Principal roles include differentiation of mesoderm into muscle and dorsoventral patterning of the neuroectoderm in concert with BMP signalling [131133]. In Lophotrochozoa, roles in the differentiation of muscle and nerve precursors have been implicated in the polychaete Platynereis [134], and in dugesiid planarians msh genes have been shown to regulate neoblast proliferation and BMP signalling during head regeneration [135]. Ovarian and uterine expression of $m s x$ genes has been shown also in mice, including a direct role in the regulation of meiosis in the female germline [136, 137]. Tapeworms lack direct orthologs of Msx family genes [35] but do possess single copies of the closely related Msxlx family which has been lost in tunicates and vertebrates [138]. Msxlx expression in Hymenolepis is clearly related to the female system, and it would be informative to know whether it is also expressed in the ovaries of planarians. However, expression in planarians has only been examined in the context of regeneration [135].

Hmic- $n k 1$ is one of two paralogs found in tapeworms [35] and is a principal member of the NKL sub-class of ANTP-type homeoboxes that also includes the closely related Msx/Msxlx family genes [139, 140]. There is a large diversity of $n k$-like genes in animals which, similar to $m s x$ genes, play fundamental roles in differentiation, proliferation and apoptosis, often in relation to neurogenesis [134, 141] and muscle patterning [142], and an $n k 1$ gene has been shown to be essential for the formation of circular muscles in Schmidtea [75]. However, a recent study of the transcriptomes of the testes and ovaries of Schistosoma mansoni showed up-regulation of an $n k 2$ gene in the ovaries of paired females, but not in the testes of males or ovaries of un-paired females [143]. Thus together with the present study, results indicate a role of NK homeobox genes in the female reproductive system in both tapeworms and flukes.

\section{otx and prox 3}

In addition to the above NKL-type homeobox genes, the ovaries also express the PRD-class gene otx (Fig. 6f) and the PROS/Prox-class homeobox prox/prospero (Fig. 6g). Notably, otx and prox 3 also show another focus of expression around the genital pores, which are highly innervated [39, 119]. Otx is orthologous [35] to Drosophila 
orthodenticle (otd) and vertebrate otx genes, canonical regulators of brain development [144]. Planarians have two otx genes that are expressed in the brain $[145,146]$, in photoreceptor neurons $[68,147]$ and in CNS-related neoblast progenitors [69].

Prospero/prox genes are also broadly involved in nervous system development and in the regulation of neural progenitor cells [148-150] and in Schmidtea have been shown to be up-regulated in proliferating cells [84] including neural progenitor neoblasts [69]. Prox2 is one of two paralogs in Hymenolepis and had few reads mapped against the v.2 genome (Additional file 1: Table S1.2) despite the strong expression seen in the ovaries, whereas Hmic-prox 1 was highly up-regulated in both the Larvae and Scolex-Neck samples (Table 2). A role of Hmic-prox 2 in the female germline of tapeworms is thus broadly consistent with stem cell-related roles in planarians. As both prox and otx genes are canonically associated with the nervous system, expression around the genital atrium is likely to be associated with its innervation. In contrast, otx has not been previously associated with the germline or reproductive tissues of animals. Simultaneous expression of these genes in the ovary and around the genital ducts points towards an intriguing link in gene regulation between these two parts of the reproductive system.

\section{foxC-like}

A tapeworm-specific foxC-like forkhead box gene shows a similar, albeit weaker, pattern of expression in both the ovary and around the genital ducts (Fig. 6h). Weak expression is also observed in the nascent genital primoridia of the female system in immature segments, appearing as central dots (not shown). Gene trees produced via WBP (not shown) indicate foxC-like to be a divergent member of the family with direct flatworm orthologs identified only in the closely related species $H$. nana and $H$. diminuta. Thus although comparison with orthologs in other animals may be dubious, the foxl 2 gene has been shown to be central to ovarian differentiation and maintenance in mammals [151].

\section{zf621400}

Of the transcripts found to be specific to the female system, only one showed expression in the vitellarium: an unclassified $\mathrm{C} 2 \mathrm{H} 2$-type zinc finger. Vitellaria represent a division of the female system between the germarium (i.e. ovary; producing oocytes) and the vitellarium (producing vitellocytes) that is found in euneoophoran flatworms, which includes the parasitic flatworms and a subset of derived, free-living groups that includes planarians (i.e. Tricladia) [152, 153]. Ectolecithal eggs are produced in which fertilised oocytes are packaged with varying numbers of vitellocytes that provide both yolk and proteins for the production of the egg shell [154]. Typical of cyclophyllidean tapeworms, H. microstoma has a single, compact vitellarium situated centrally, below the bi-lobed ovary [42]. Hmic-zf621400 expression is seen throughout the developing and mature vitellaria in the strobila (Fig. 6i) and in individual cells (putatively vitellocytes) in the uterus, showing that it continues to be expressed during embryogenesis (Additional file 5: Figure S1). However, in addition to the vitellaria, expression is also observed in somatic cells and in the genital primordia of immature segments (Additional file 5: Figure S1). Hence, it may be that this transcription factor had a more general role in flatworms and secondarily evolved a role in vitellogenesis in the Euneophora. A molecular marker for tapeworm vitellaria has not been reported previously, and thus, the gene may find utility for this purpose. A large number of vitellaria- and/or vitellocyte-specific genes were identified in blood flukes through a similar combination of RNA-seq and WMISH [155], and many of these may prove to be useful markers in other parasitic flatworms and other euneophoran groups.

\section{zyg11-like}

A zyg11-like gene is up-regulated in the Mid and End samples (cf. Scolex-Neck) and was one of a small number of tapeworm orthologs identified among a list of candidate senescence-related genes in C. elegans (unpub. data). In Hymenolepis, it shows diffuse expression throughout the uterus, revealing the anastomosing structure of the organ (Fig. 6j). Zyg11 encodes a member of a large protein family characterised by leucine-rich repeats and is involved in several functions in C. elegans including meiotic progression and AP polarity during embryogenesis $[156,157]$. Functions of the gene family outside of C. elegans are not known. Hmic-zyg11-like is one of 12 paralogs in the $H$. microstoma genome, and phylogenetic analysis via WBP (not shown) indicates that it is part of a large expansion of this gene family in parasitic flatworms. Its spatial expression suggests it could be a marker for the uterus.

\section{Differential expression in the gravid strobila}

A comparatively small number of DE GOI were identified in the End sample (Table 2) as discussed previously, and none showed high log2fold-change values. In addition to five putative zinc fingers, there was a small number of homeoboxes, high mobility group and basic leucine zipper transcription factors identified (Table 2). Among signalling components was an FGF receptor also up-regulated in Larvae (discussed above) and a slit-like protein sequence that was the only example among GOI of the Slit/Robo pathway which is canonically involved in axon 
repulsion during neural development [158]. A paralog of the smad-like factor DE in the Mid sample was identified as were components of Wnt signalling, including the Wnt antagonist $s f r p$ which is involved in establishing primary AP polarity in animals [159] and in tapeworms is expressed at the site(s) of scolex formation in developing Larvae [63]. A paralog of the stem cell regulator pumillio (cf. Mid sample) was highly expressed, albeit only around twice the level of its expression in the Mid and ScolexNeck samples (log2fold change of 0.8; Table 2). No gene was examined by WMISH in the End sample.

\section{Conclusions}

Through genome-wide transcriptome profiling we have identified genes DE in association with the major stages of the H. microstoma life cycle, revealing candidate regulators of the underlying developmental processes. Spatial analyses corroborate quantitative RNA-seq data and provide insights into the putative roles of the genes by linking their expression to organs, tissues and cells in tapeworms for the first time. The overarching picture shows that their complex development involves factors with canonical roles in axial specification, neurogenesis, myogenesis and stem cell regulation and that their underlying developmental 'toolkit' therefore resembles that of free-living flatworms and metazoan animals in general. The striking similarity in transcriptome profiles of the Scolex-Neck region and Larvae, both in general and specifically in relation to genes known to be involved in animal development, suggests that strobilation in adults involves recapitulation of many of the same gene regulatory networks employed during larval metamorphosis. In contrast, reproductive development involves a larger percentage of up-regulated genes that lack clear orthologs in other animal groups.

Our work represents a course-grained survey of differential gene expression in tapeworms and a finer-grained approach including more time points during larval metamorphosis and smaller divisions of the adult body would reveal additional $\mathrm{DE}$ genes and provide a more refined overview of their temporal expression dynamics. Broad surveys of this type are especially critical in new model organisms and have been integral to elucidating gene regulatory networks in planarians [21]. Recent addition of long-read and optical mapping data has now improved H. microstoma genome assembly to the level of full chromosomes (unpub. data), which will make it among, if not the, most complete genome of a lophotrochozoan, and will stabilise gene model estimates. The development of such genomic resources for parasitic flatworms and their curation via WormBase ParaSite [45] has accelerated our ability to investigate their developmental genetics. Moreover, increased representation of species through the 50 Helminth Genomes Project [160] means that we can make more comprehensive investigations of the diversity and interrelationships of developmentally related genes to determine their degree of taxonomic restriction (i.e. 'orphan-ness') [161, 162] and to identify where direct orthologs exist between free-living and parasitic species.

Understanding the somatic stem cell systems of parasitic flatworms is essential to investigations of all aspects of their growth and differentiation. Germinative cells of tapeworms and neoblast-like cells of blood flukes have been a focus of recent studies that demonstrate similarities with planarians as well as potentially significant differences in their underlying regulation $[14,15,36,37$, $100,163,164]$. Transcriptional profiling of their proliferative cell compartments will allow us to determine the full extent to which regulation differs from the well-characterised neoblast system of planarians, and we expect that single-cell profiling will reveal sub-populations of partly differentiated progenitor stem cells, as recently characterised in Schmidtea mediterranea [69, 165]. Such studies would provide new candidate targets for chemotherapy as well as an abundance of cell-specific markers that will enable expressed genes to be associated with different cellular compartments.

\section{Methods}

\section{Animal cultures and samples}

The Nottingham strain [42] of the mouse bile-duct tapeworm, Hymenolepis microstoma, was maintained in vivo using flour beetles (Tribolium confusum and T. castaneum) and inbred strains of laboratory mice (Mus musculus) in accordance with project licence PPL70/8684 issued by the UK Home Office to PDO. To produce larval samples representing the approximate mid-point in the metamorphosis from oncosphere to cysticercoid, beetles were starved for five days and then exposed to macerated, gravid proglottids of $H$. microstoma for $\sim 6 \mathrm{~h}$. Gravid tissues were removed, and the beetles allowed to feed on flour ad libitum. Beetles were dissected five days post-exposure to eggs and the Larvae collected from the haemocoel and transferred live into RNAlater (Qiagen). Morphologically, most Larvae were elongated and well differentiated at both poles, equating to stage 3 following Voge [166]. However, individual variation in developmental rates meant that some Larvae were closer to 'stages' 2 or 4 . Approximately 550 individuals were combined for each of three replicate larval samples and stored in RNAlater at $-80^{\circ} \mathrm{C}$.

For the Whole Adult samples, fully grown, gravid worms $>1$ month old were dissected from the bile ducts of mice into vertebrate saline $(0.85 \% \mathrm{w} / \mathrm{v} \mathrm{NaCl})$, rinsed 
and preserved live in RNAlater before storing at $-80{ }^{\circ} \mathrm{C}$. Three entire worms were used as replicates for the Whole Adult samples.

For the regional samples of the adult worm, whole worms were removed from mice and swirled in near boiling saline to extend and kill the worms. They were then straightened in a petri dish while immersed in RNAlater, worms of similar length aligned, and comparable regions of the strobili cut from multiple worms and pooled. The Scolex-Neck samples included the scolex, neck and some number of nascent segments (total sample length apx. $0.5 \mathrm{~cm}$ from apex) and consisted of tissues combined from 13 to 43 individuals/replicate. The Mid samples consisted of $\sim 2.5 \mathrm{~cm}$ lengths of tissue representing not the actual mid-point of the strobila, but a position roughly $2 / 3$ of the length from the apex where both the male and female systems are mature (Fig. 1a) and were combined from 11 to 17 individuals/replicate. The End samples consisted of $\sim 2.5 \mathrm{~cm}$ lengths of gravid, sub-terminal tissues combined from 11 to 14 individuals/ replicate.

For in situ hybridisation, adult tapeworms were harvested from mouse bile ducts into saline and swirled for $\sim 2 \mathrm{~s}$ in near boiling saline to extend and kill the worms as above. They were then fixed in fresh, cold $4 \% \mathrm{w} / \mathrm{v}$ paraformaldehyde (PFA) in phosphate-buffered saline (PBS) overnight at $4{ }^{\circ} \mathrm{C}$ before being transferred to PBSAT (PBS and $0.1 \% \mathrm{v} / \mathrm{v}$ Tween 20 ) or dehydrated in a graded series of ethanol and PBS and stored at $4{ }^{\circ} \mathrm{C}$. Whole worms were rehydrated in PBSAT and cut into $2-4 \mathrm{~cm}$ sections prior to WMISH. Larval worms were produced as described above, and developmental series of Larvae were generated by sub-sampling infected beetles on days 3, 4, 5, 6 and 7 post-exposure to eggs and then fixing them directly in RNAlater. Prior to processing, the Larvae were visually sorted into 'stages' (Fig. 1a) and 5-10 individuals of each stage combined into individual tubes to be processed simultaneously. Further details on the culturing of $H$. microstoma are available at www.olsonlab.com.

\section{Transcriptome sequencing}

Total RNA was prepared by washing each sample in icecold PBS before being mechanically homogenised in Trizol (Invitrogen) and extracted with 24:1 chloroform/ isoamyl alcohol. Phase separation was carried out by centrifugation at $4{ }^{\circ} \mathrm{C}$. 0.5 volumes isopropanol, and $4 \mu \mathrm{l}$ of glycogen $(5 \mathrm{mg} / \mathrm{ml})$ was added to the aqueous phase, and total RNA was precipitated at $-80^{\circ} \mathrm{C}$ for $1 \mathrm{~h}$. RNA was pelleted, washed with fresh $75 \% \mathrm{v} / \mathrm{v}$ ethanol, re-suspended in nuclease-free water and quality-checked and quantified using an Agilent Bioanalyzer 2100. Libraries for transcriptome sequencing were prepared using the TruSeq kit (Illumina) with polyadenylated mRNA selected using oligo-dT Dynabeads. After cDNA synthesis, adaptors were ligated and libraries were amplified by PCR using Kapa HiFi DNA polymerase (Kapa Biosystems). Amplified templates were purified with AMPure SPRI beads, quantified using a Bioanalyzer (Agilent) and pooled. From pooled libraries, 300- to 400-bp fragments were selected using the Caliper system. After adaptor ligation, individual libraries made with the Illumina mRNA-seq kit were size-selected using the Caliper system before PCR amplification followed by AMPure SPRI bead clean up and removal of adaptors with a second Caliper run. Kapa Illumina SYBR Fast qPCR kit was used to quantify the Illumina mRNA-seq libraries before pooling. Libraries were sequenced using v4 Cluster Generation and v5 Sequence-by-Synthesis kits, according to the manufacturer's protocols (Illumina), to produce paired 76- or 100-base reads. Primary analysis of raw data generated by the Illumina HiSeq genome sequencer was performed with the RTA v.1.8 analysis pipeline. Accession numbers of the generated sample data are given in Additional file 1: Table S1.1.

\section{Hymenolepis microstoma v.2 genome assembly}

Analyses were based on the latest publicly available version of the H. microstoma genome and gene models (v.2) curated on WormBase ParaSite (parasite.wormbase. org) [45] under accession PRJEB124. This represents an unpublished update to the v.1 assembly published in [35] and has not been previously described. Version 2 is based on the incorporation of an additional lane of Illumina HiSeq data from the library ENA002564 (https://www. ebi.ac.uk/arrayexpress/) and re-assembly of the genome as follows. The v.1 genome was quality-checked using REAPR v.1.0.15 [167]. Low-confidence scaffolds were broken, and all sequence data were mapped back to the genome. Unmapped reads were assembled using Velvet v.1.2.09 with a kmer size of 57 [168]. Resulting contigs longer than $500 \mathrm{bp}$ were merged with the REAPR-corrected genome and scaffolded using three iterations of SSPACE v.1.1 [169]. Gaps were filled using several increasingly permissive iterations of GapFiller v.1.11 until saturation was achieved [170]. The process of breaking and re-joining was repeated until only marginal returns could be achieved. Contigs shorter than 500 bp were excluded and consensus bases corrected using iCORN for three iterations. Using PROmer from the MUMmer package v.3.23 [171], it was observed that the H. microstoma genome is largely co-linear with that of the fox tapeworm Echinococcus multilocularis. The H. microstoma genome was thus ordered following orthologs to E. multilocularis using ABACAS v.2 [172]. As scaffolds were joined on orthology evidence, the resulting gene order may be incorrect if it has changed during evolution, 
but it represents our current best hypothesis of the interrelationships among contigs. The resulting v. 2 assembly is $16 \%$ larger than v. 1 and includes longer scaffolds and contigs.

Gene models were transferred from version 1 to 2 (7981 models transferred out of 10,149). As v.2 is larger than v.1, new gene models were predicted using Augustus v2.5.5 [173] with and without RNA-seq support. Only unique gene models not overlapping with a previously identified model were retained and in total, 2222 new gene models (of 12,368 in total) were included in the current set. Gene models were annotated using a custom pipeline as described in section S5 of [35]. In brief, annotations were made from the product calls of the top ten matches in the GenBank nr database where they had $e$ values $<0.0001$. For predicted proteins lacking such similarity to known sequences, annotation was made from any domains identified in the protein using InterProScan. Remaining proteins lacking domain predictions were annotated as novel as described in Results and Discussion. All genome data and annotations are available via WormBase ParaSite [45] at parasite.wormbase.org.

\section{Differential expression analyses}

Paired-end RNA-seq reads from a total of 18 technical and sample replicates (Additional file 1: Table S1.1) were mapped to the genome using TopHat v.1.4.1 [174] and FPKM values (fragments per kilobase per million mapped reads) calculated for each gene model using the Cuffdiff programme included in the Cufflinks package (v.2.0.2; default parameters plus $-\mathrm{u}$ and $-\mathrm{b}$ options [174]). Raw and normalised mapped reads per gene model and sample replicate are given in Additional file 1: Tables S1.2 and S1.3, respectively. Differentially expressed genes were determined using DESeq2 v.1.14 [175]. Comparisons were made between the Larvae and Whole Adult samples and among each of the three regional samples (i.e. Scolex-Neck cf. Mid, Scolex-Neck cf. End, and Mid cf. End) as described in Results and Discussion. Raw counts per replicate were used as input, and the two technical replicates for each of the Larvae samples were combined using the collapseReplicate function. DESeq2-transformed and DESeq2-adjusted gene model expression levels between samples differing from zero at a confidence level of 0.00001 were considered differentially expressed and were ranked by their log2fold change. Complete lists of up- and down-regulated gene models for each contrast are given in Additional file 2: Tables S2.1-S2.5, and the intersects of up-regulated genes for each of the regional samples compared with the other two are given in Additional file 2: Tables S2.6-S2.8.

To investigate overall similarities/differences among the samples and replicates, we plotted the first two principal components of the libraries using the dists and plotPCA functions (Fig. 1b) and constructed a heatmap of the sample-to-sample distances using the pheatmap function (Fig. 1c). In addition, we constructed heatmaps based on normalised expression means of three suites of gene models: (1) all homeobox transcription factors (Fig. 2a); (2) all components of Wnt, Notch and Hedgehog signalling pathways (Fig. 2b), and (3) all unique GOI identified herein. Homeoboxes and signalling components are identified in Supplementary Tables S10.1 and S10.2, respectively, in [35], and GOI identified here are listed in Table 2 and Additional file 4: Table S4.

\section{Gene Ontology analyses}

Gene Ontology [176] terms associated with the gene models were retrieved from WBP using the Biomart function and are included in Additional file 2: Tables S2.2-S2.5 and summarised in Additional file 3: Tables S3.1-S3.7. Biological process terms were mapped to GO slims using bespoke java code and GO version 201807-17. Enrichment of GO biological process terms was calculated for the DE genes using the goseq $\mathrm{R}$ package (version 1.32.0) and GO.db (version 3.6.0). Terms were considered significant (i.e. enriched) at a $p$ value threshold of 0.05 after adjustment using the Benjamini-Hochberg false-discovery rate. REVIGO (revigo.irb.hr) [49] was used to summarise GO annotations to sets of differentially expressed genes using a threshold of 0.4 and the SimRel similarity measure.

\section{Gene cloning and probe synthesis}

Gene-specific primers (Additional File 6: Table S5) were designed using Primer3 [177] implemented in Geneious v.8 (Biomatters) against predicted gene model sequences. Parameters were set to produce optimal product sizes of $1-1.5 \mathrm{~Kb}$ and to anneal at least $50 \mathrm{bp}$ internally from the ends to increase their efficiency in cases where template cDNAs were not full length. Transcripts were amplified by PCR from cDNAs synthesised from total RNA purified from either Whole Adult or pooled, larval worms. Products were cloned using a StrataClone PCR cloning kit (Agilent Technologies) according to the manufacturer's instructions, except that all volumes were halved. Transformed plaques were picked and added to $500 \mu \mathrm{l}$ water, heated to $80{ }^{\circ} \mathrm{C}$ to liberate the plasmids, and the resulting mixture used as template for further amplification by PCR using M13 primers. Resulting products (consisting of the gene insert flanked by T3/T7 reverse transcriptase promoter regions and M13 priming sites) were cleaned, quantified and used as templates for probe synthesis. Digoxigenin (DIG)-labelled riboprobes were synthesised from both the sense $(+)$ and anti-sense $(-)$ 
strands using T3 and T7 reverse transcriptases and DIGRNA labelling mix (Roche).

\section{Whole-mount in situ hybridisation}

Assays were performed in 1.5-ml Eppendorf tubes that were placed in 50-ml Falcon tubes on a roller to provide continuous agitation during washing steps. A minimum of five worms/assay was used for adults as well as for each larval stage, and separate assays performed for the sense (control) and anti-sense probes. Some assays were repeated two or more times to improve results. PFA-fixed specimens were rehydrated in PBSAT and then permeabilised in $10 \mu \mathrm{g} / \mathrm{ml}$ proteinase $\mathrm{K}$ in PBSAT for 10 (adult worms) or 5 (Larvae) mins at room temperature (RT) and then rinsed in $0.1 \mathrm{M}$ triethanolamine pH 7.8 (TEA) followed by $0.25 \% \mathrm{v} / \mathrm{v}$ acetic anhydride in $0.1 \mathrm{M}$ TEA then $0.5 \% \mathrm{v} / \mathrm{v}$ acetic anhydride in $0.1 \mathrm{M}$ TEA, before being washed in PBSAT. They were postfixed in fresh $4 \% \mathrm{w} / \mathrm{v}$ PFA in PBS for $20 \mathrm{~min}$ at RT and thoroughly rinsed in PBSAT. Specimens were equilibrated with hybridisation buffer $(50 \% \mathrm{v} / \mathrm{v}$ formamide (Sigma), $5 \times$ saline-sodium citrate buffer (SSC), $100 \mu \mathrm{g} /$ $\mathrm{ml}$ heparin (Sigma), $1 \times$ Denhardt's solution (Sigma), $0.1 \% \mathrm{v} / \mathrm{v}$ Tween 20 (Sigma), 0.1\% v/v CHAPS (Sigma), $10 \mathrm{mM}$ EDTA) then prehybridised at $60{ }^{\circ} \mathrm{C}$ in hybridisation + buffer, which is hybridisation buffer containing $1 \mathrm{mg} / \mathrm{ml}$ yeast RNA (Roche). This was replaced with fresh, pre-warmed hybridisation + buffer containing riboprobe at a concentration of $1 \mu \mathrm{g} / \mathrm{ml}$ and hybridised overnight at $60{ }^{\circ} \mathrm{C}$ using a shaking heating block. Probe/ hybridisation buffer was removed and stored frozen for future use and the specimens rinsed in pre-warmed hybridisation + buffer to remove unbound probe. Specimens were then washed in $2 \mathrm{x}$ SSC followed by $0.2 \mathrm{x}$ SSC buffer (made by dilution in nuclease-free water of $20 \times$ SSC, which is $3 \mathrm{M}$ sodium chloride and $300 \mathrm{mM}$ trisodium citrate in water, $\mathrm{pH} 7$ ), then in $0.1 \mathrm{M}$ maleic acid buffer $\mathrm{pH} 7.8(\mathrm{MAB})$ at RT. This was replaced with blocking buffer consisting of MAB containing $2 \%$ $\mathrm{w} / \mathrm{v}$ bovine serum albumin and $20 \% \mathrm{v} / \mathrm{v}$ heat inactivated lamb serum and incubated for $2 \mathrm{~h}$ at RT. This was replaced by fresh solution containing a 1:2000 dilution of anti-DIG antibody coupled to alkaline phosphatase (Roche) and incubated overnight at $4{ }^{\circ} \mathrm{C}$. Antibody solution was removed and the specimens thoroughly washed at RT in MAB followed by alkaline phosphatase buffer. Specimens were transferred to watch glasses, NBT/BCIP (Roche) was added and the specimens left to incubate at RT (or overnight at $4{ }^{\circ} \mathrm{C}$ ) until a colour reaction was observed. They were then rinsed in PBSAT, post-fixed in 4\% w/v PFA in PBS for $1 \mathrm{~h}$, rinsed further in PBSAT and dehydrated in a graded ethanol series. Specimens were cleared in a 1:1 mixture of benzyl alcohol and benzyl benzoate, mounted on microscope slides and stored at $4{ }^{\circ} \mathrm{C}$. WMISH and other protocols can be found on www.olsonlab.com. Mounted specimens were imaged on a Leica DM5000B compound microscope with differential interference contrast and a Leica DFC450C digital camera controlled by Leica Application Suite ver. 4. Images were cropped, and in some cases the overall brightness and/ or contrast were digitally enhanced, but no other photo manipulation was made.

\section{Additional files}

Additional file 1. Raw and normalised read counts per gene model and sample replicate. Table S1.1. RNA-seq sample accessions. Table S1.2. RNA-seq mapped read counts by gene model and sample replicate. Table S1.3. Normalised (FPKM) mapped read counts by gene model and sample replicate.

Additional file 2. Ranked lists of differentially expressed genes for each comparison, showing log2fold changes, mean normalised counts, adjusted $p$ values and Gene Ontology terms. Table S2.1. Summary of differential expression. Table S2.2. Larval cf. Whole Adult. Table S2.3. Scolex-Neck cf. Mid. Table S2.4. Scolex-Neck cf. End. Table S2.5. Mid cf. End. Table S2.6. Intersection of up-regulated genes between the ScolexNeck cf. Mid and Scolex-Neck cf. End contrasts. Table S2.7. Intersection of up-regulated genes between the Mid cf. Scolex-Neck and Mid cf. End contrasts. Table S2.8. Intersection of up-regulated genes between the End cf. Scolex-Neck and End cf. Mid contrasts.

Additional file 3. REVIGO [49] summarised Gene Ontology biological process terms associated with differentially expressed gene models. Table S3.1. Larvae cf. Whole Adult. Table S3.2. Scolex-Neck cf. Mid. Table S3.3. Scolex-Neck cf. End. Table S3.4. Mid cf. Scolex-Neck. Table S3.5. Mid cf. End. Table S3.6. End cf. Scolex-Neck. Table S3.7. End cf. Mid.

Additional file 4: Table S4. Zinc finger transcription factor genes of interest.

Additional file 5: Figure S1. Vitellarium-associated and additional expression foci of the putative zinc finger transcription factor Hmic-zf621400. A Enlarged view of vitellarium expression in mature segments (boxed region of inset). B-C Punctate expression is also seen in some specimens, especially in immature segments (arrows show nascent seminal receptacles). D Expression by vitelline cells distributed with ova becomes visible in the uterus of mature segments. Abbreviations: esv, external seminal vesicle; gp, genital pore; isv, internal seminal vesicle; $s$, seminal receptacle; $t$, testis; u, uterus; vt, vitellarium. scale bars $100 \mu \mathrm{m}(\mathbf{A}, \mathbf{D}), 200 \mu \mathrm{m}$ (B, C).

Additional file 6: Table S5. Gene-specific primers and predicted protein sequences of transcripts examined by WMISH.

\section{Abbreviations}

CNS: central nervous system; DE: differentially expressed; FPKM: fragments per kilobase of transcript per million mapped reads; GO: Gene Ontology; WBP: WormBase ParaSite (parasite.wormbase.org); WMISH: whole-mount in situ hybridisation.

\section{Authors' contributions}

PDO conceived the study, performed analyses and prepared and wrote the manuscript with input from co-authors. MZ, KJ, PDO, NH and MB coordinated and generated RNA-seq data and performed bioinformatic analyses. MZ assembled the H. microstoma v.2 genome and mapped RNA-seq data. KJ 
performed differential expression and Gene Ontology analyses. AB, GB, PB, AC, FJ and LYT performed or assisted with in situ hybridisation assays. All authors read and approved the final manuscript.

\section{Author details}

${ }^{1}$ Division of Parasites and Vectors, Department of Life Sciences, The Natural History Museum, Cromwell Road, London SW7 5BD, UK. ${ }^{2}$ Parasite Genomics, Wellcome Trust Sanger Institute, Wellcome Trust Genome Campus, Hinxton, Cambridge CB10 1SA, UK.

\section{Acknowledgements}

Thanks to Uriel Koziol and two anonymous reviewers for commenting on an earlier draft of the paper, Alejandro Sanchez-Flores for initial differential expression analyses based on a draft version of the genome, Thomas Huckvale for RNA extractions and Loren Selby for identification and WMISH of zyg 17 -like. Samples for RNA sequencing were prepared by PDO and Natasha PouchkinaStantcheva who was supported by a BBSRC Grant to PDO (BBG0038151).

\section{Competing interests}

The authors declare they have no competing interest.

\section{Availability of data and materials}

RNA-seq data are publicly available in the European Nucleotide Archive and Array Express under accessions PRJEB5096 and E-ERAD-236, respectively. Genome data and gene models are available via WormBase ParaSite (wormbase.parasite.org). Seed cultures of $H$. microstoma are available on request from PDO.

\section{Consent for publication}

Not applicable.

\section{Ethics approval and consent to participate}

Mice were used in accordance with project licence PPL70/8684 issued by the UK Home Office to PDO.

\section{Funding}

MZ was supported in part by a SynTax joint UK Research Council grant to PDO and MB. Sequencing was funded by the Wellcome Trust (Grant WT098051 to $M B)$.

\section{Publisher's Note}

Springer Nature remains neutral with regard to jurisdictional claims in published maps and institutional affiliations.

Received: 5 March 2018 Accepted: 5 October 2018

Published online: 09 November 2018

\section{References}

1. Blair SS. Segmentation in animals. Curr Biol. 2008;18:R991-5.

2. Minelli A. The tapeworm's elusive antero-posterior polarity. BMC Biol. 2016;14:1-3.

3. Egger B. Making heads or tails of tapeworms. Trends Parasitol. 2016;32:511-2.

4. Hotez PJ, Alvarado M, Basanez M-G, Bolliger I, Bourne R, Boussinesq $M$, et al. The global burden of disease study 2010: interpretation and implications for the neglected tropical diseases. PLoS Negl Trop Dis. 2014;8:e2865

5. Molyneux DH, Savioli L, Engels D. Neglected tropical diseases: progress towards addressing the chronic pandemic. Lancet. 2016;380:1-14.

6. Soares Magalhães RJ, Fançony C, Gamboa D, Langa AJ, Sousa-Figueiredo JC, Clements ACA, et al. Extending helminth control beyond STH and schistosomiasis: the case of human hymenolepiasis. PLoS Negl Trop Dis. 2013;7:e2321.

7. Ashford RW, Crewe W. The parasites of Homo sapiens. 2nd ed. London: Taylor \& Francis; 2003.

8. SantamariaFries M, Fajardo L-GLF, Sogin ML, Olson PD, Relman DA. Lethal infection by a previously unrecognised metazoan parasite. Lancet. 1996;347:1797-801.
9. Muehlenbachs A, Bhatnagar J, Agudelo CA, Hidron A, Eberhard ML, Mathison BA, et al. Malignant transformation of Hymenolepis nana in a human host. N Engl J Med. 2015;373:1845-52.

10. Olson PD. Hox genes and the parasitic flatworms: new opportunities, challenges and lessons from the free-living. Parasitol Int. 2008;57:8-17.

11. Collins JJ, Newmark PA. It's no fluke: the planarian as a model for understanding schistosomes. PLoS Pathog. 2013;9:e1003396-6.

12. Koziol U. Evolutionary developmental biology (evo-devo) of cestodes. Exp Parasitol. 2017;180:84-100.

13. Skinner DE, Rinaldi G, Koziol U, Brehm K. How might flukes and tapeworms maintain genome integrity without a canonical piRNA pathway? Trends Parasitol. 2014;30:123-9.

14. Collins JJ, Wang B, Lambrus BG, Tharp ME, Iyer H, Newmark PA. Adult somatic stem cells in the human parasite Schistosoma mansoni. Nature. 2013:494:1-5.

15. Koziol U, Rauschendorfer T, Rodríguez LZ, Brehm K. The unique stem cell system of the immortal larva of the human parasite Echinococcus multilocularis. EvoDevo. 2014;5:10.

16. Wendt GR, Collins JJl. Schistosomiasis as a disease of stem cells. Curr Opin Genet Dev. 2016:40:95-102.

17. Brehm K, Koziol U. On the importance of targeting parasite stem cells in anti-echinococcosis drug development. Parasite. 2014;21:72.

18. Robb SMC, Ross E, Sánchez Alvarado A. SmedGD: the Schmidtea mediterranea genome database. Nucleic Acids Res. 2007;36:D599-606.

19. Robb SMC, Gotting K, Ross E, Sánchez Alvarado A. The Schmidtea mediterranea genome database. Genesis. 2015;53:535-46.

20. Sánchez Alvarado A, Newmark PA. Double-stranded RNA specifically disrupts gene expression during planarian regeneration. Proc Natl Acad Sci USA. 1999;96:5049-54.

21. Reddien PW, Bermange AL, Murfitt KJ, Jennings JR, Sánchez Alvarado A. Identification of genes needed for regeneration, stem cell function, and tissue homeostasis by systematic gene perturbation in planaria. Dev Cell. 2005;8:635-49.

22. Rouhana L, Weiss JA, Forsthoefel DJ, Lee H, King RS, Inoue T, et al. RNA interference by feeding in vitro-synthesized double-stranded RNA to planarians: methodology and dynamics. Dev Dyn. 2013;242:718-30.

23. Newmark PA, Sánchez Alvarado A. Not your father's planarian: a classical model enters the era of functional genomics. Nat Rev Genet. 2002;3:210-9.

24. Newmark PA, Sánchez Alvarado A. Bromodeoxyuridine specifically labels the regenerative stem cells of planarians. Dev Biol. 2000;220:142-53.

25. Reddien PW, Oviedo NJ, Jennings JR, Jenkin JC, Sánchez Alvarado A. SMEDWI-2 is a PIWI-like protein that regulates planarian stem cells. Science. 2005;310:1327-30.

26. Zhu SJ, Pearson BJ. (Neo)blast from the past: new insights into planarian stem cell lineages. Curr Opin Genet Dev. 2016;40:74-80.

27. Peter R, Gschwentner R, Schürmann W, Rieger RM, Ladurner P. The significance of stem cells in free-living flatworms: one common source for all cells in the adult. J App Biomed. 2004;2:21-35.

28. Reddien PW. Constitutive gene expression and the specification of tissue identity in adult planarian biology. Trends Genet. 2011;27:277-85.

29. Petersen CP, Reddien PW. Smed-betacatenin-1 is required for anteroposterior blastema polarity in planarian regeneration. Science. 2008;319:327-30.

30. Gurley KA, Rink JC, Alvarado AS. Smed-Bcatenin-1 defines head versus tail identity during planarian regeneration and homeostasis. Science. 2008;319:323-7.

31. Iglesias M, Gomez-Skarmeta JL, Adell T. Silencing of Smed-Bcatenin 1 generates radial-like hypercephalized planarians. Development. 2008;135:1215-21.

32. Berriman M, Wilson RA, Dillon GP, Cerqueira GC, Ashton PD, Aslett MA, et al. The genome of the blood fluke Schistosoma mansoni. Nature. 2009;460:352-8.

33. Protasio AV, Tsai IJ, Babbage A, Nichol S, Hunt M, Aslett MA, et al. A systematically improved high quality genome and transcriptome of the human blood fluke Schistosoma mansoni. PLoS Negl Trop Dis. 2012;6:e1455-13.

34. Olson PD, Zarowiecki M, Kiss F, Brehm K. Cestode genomics—progress and prospects for advancing basic and applied aspects of flatworm biology. Parasite Immunol. 2012;34:130-50. 
35. Tsai IJ, Zarowiecki M, Holroyd N, Brooks KL, Tracey A, Bobes RJ, et al. The genomes of four tapeworm species reveal adaptations to parasitism. Nature. 2013:496:57-63.

36. Wang B, Collins JJl, Newmark PA. Functional genomic characterization of neoblast-like stem cells in larval Schistosoma mansoni. eLife. 2013;2:e00768.

37. Koziol U, Domínguez MF, Marín M, Kun A, Castillo E. Stem cell proliferation during in vitro development of the model cestode Mesocestoides corti from larva to adult worm. Front Zool. 2010;7:22.

38. Collins JJ, King RS, Cogswell AA, Williams DL, Newmark PA. An atlas for Schistosoma mansoni organs and life-cycle stages using cell type-specific markers and confocal microscopy. PLoS Negl Trop Dis. 2011:5:e1009.

39. Rozario T, Newmark PA. A confocal microscopy-based atlas of tissue architecture in the tapeworm Hymenolepis diminuta. Exp Parasitol. 2015;158:31-41.

40. Cogswell AA, Collins JJ, Newmark PA, Williams DL. Whole mount in situ hybridization methodology for Schistosoma mansoni. Mol Biochem Parasitol. 2011;178:46-50.

41. Bizarro CV, Bengtson MH, Ricachenevsky FK, Zaha A, Sogayar MC, Ferreira HB. Differentially expressed sequences from a cestode parasite reveals conserved developmental genes in platyhelminthes. Mol Biochem Parasitol. 2005;144:114-8.

42. Cunningham LJ, Olson PD. Description of Hymenolepis microstoma (Nottingham strain): a classical tapeworm model for research in the genomic era. Parasites Vectors. 2010;3:123.

43. Zeitlinger J, Stark A. Developmental gene regulation in the era of genomics. Dev Biol. 2010;339:230-9.

44. Howe KL, Bolt BJ, Cain S, Chan J, Chen WJ, Davis P, et al. WormBase 2016: expanding to enable helminth genomic research. Nucleic Acids Res. 2015:44:D774-80.

45. Howe KL, Bolt BJ, Shafie M, Kersey P, Berriman M. WormBase ParaSite-a comprehensive resource for helminth genomics. Mol Biochem Parasitol. 2017;215:2-10.

46. Ashburner M, Ball CA, Blake JA, Botstein D, Butler H, Cherry JM, et al. Gene Ontology: tool for the unification of biology. Nat Genet. 2000;25:25-9.

47. The Gene Ontology Consortium. Expansion of the Gene Ontology knowledgebase and resources. Nucleic Acids Res. 2017;45:D331-8.

48. Young MD, Wakefield MJ, Smyth GK, Oshlack A. Gene ontology analysis for RNA-seq: accounting for selection bias. Genome Biol. 2010;11:R14.

49. Supek F, Bošnjak M, Skunca N, Šmuc T. REVIGO summarizes and visualizes long lists of gene ontology terms. PLoS ONE. 2011;6:e21800-9.

50. Mar Albà M. Zinc-finger domains in metazoans: evolution gone wild. Genome Biol. 2017;18:168.

51. Juliano CE, Swartz SZ, Wessel GM. A conserved germline multipotency program. Development. 2010;137:4113-26.

52. Pearson BJ, Sánchez Alvarado A. A planarian p53 homolog regulates proliferation and self-renewal in adult stem cell lineages. Development. 2010;137:213.

53. Halton DW, Maule AG. Flatworm nerve-muscle: structural and functional analysis. Can J Zool. 2004:82:316-33.

54. Bozzi Y, Casarosa S, Caleo M. Epilepsy as a neurodevelopmental disorder. Front Psychiatry. 2012;3:19.

55. Beermann A, Schröder R. Functional stability of the aristaless gene in appendage tip formation during evolution. Dev Genes Evol. 2004;214:303-8.

56. Campbell G, Tomlinson A. The roles of the homeobox genes aristaless and Distal-less in patterning the legs and wings of Drosophila. Development. 1998;125:4483-93.

57. Miyawaki K, Inoue Y, Mito T, Fujimoto T, Matsushima K, Shinmyo Y, et al. Expression patterns of aristaless in developing appendages of Gryllus bimaculatus (cricket). Mech Dev. 2002;113:181-4.

58. Smith KM, Gee L, Bode HR. HyAlx, an aristaless-related gene, is involved in tentacle formation in hydra. Development. 2000;127:4743-52.

59. Holland P. Evolution of homeobox genes. WIREs Dev Biol. 2013;2:31-45.

60. Fröbius AC, Seaver EC. Capitella sp., I homeobrain-like, the first lophotrochozoan member of a novel paired-like homeobox gene family. Gene Expr Patterns. 2006;6:985-91.
61. Mazza ME, Pang K, Reitzel AM, Martindale MQ, Finnerty JR. A conserved cluster of three PRD-class homeobox genes (homeobrain, $r x$ and orthopedia) in the Cnidaria and Protostomia. EvoDevo. 2010;1:3.

62. Umesono Y, Watanabe K, Agata K. A planarian orthopedia homolog is specifically expressed in the branch region of both the mature and regenerating brain. Dev Growth Differ. 1997;39:723-7.

63. Koziol U, Jarero F, Olson PD, Brehm K. Comparative analysis of Wht expression identifies a highly conserved developmental transition in flatworms. BMC Biol. 2016;14:10

64. Yu JK, Holland ND, Holland LZ. AmphiFoxQ2, a novel winged helix/ forkhead gene, exclusively marks the anterior end of the amphioxus embryo. Dev Genes Evol. 2003;213:102-5.

65. Sinigaglia C, Busengdal H, Leclère L, Technau U, Rentzsch F. The bilaterian head patterning gene six $3 / 6$ controls aboral domain development in a cnidarian. PLoS Biol. 2013;11:e1001488.

66. Fritzenwanker JH, Gerhart J, Freeman RM, Lowe CJ. The Fox/Forkhead transcription factor family of the hemichordate Saccoglossus kowalevskii. EvoDevo. 2014:5:17.

67. Hunnekuhl VS, Akam M. An anterior medial cell population with an apical-organ-like transcriptional profile that pioneers the central nervous system in the centipede Strigamia maritima. Dev Biol. 2014;396:136-49.

68. Lapan SW, Reddien PW. dlx and sp6-9 Control optic cup regeneration in a prototypic eye. PLoS Genet. 2011;7:e1002226.

69. Scimone ML, Kravarik KM, Lapan SW, Reddien PW. Neoblast specialization in regeneration of the planarian Schmidtea mediterranea. Stem Cell Rep. 2014;3:339-52.

70. Andrikou C, Arnone MI. Too many ways to make a muscle: evolution of GRNs governing myogenesis. Zool Anz. 2015;256:2-13.

71. Tapscott SJ. The circuitry of a master switch: myod and the regulation of skeletal muscle gene transcription. Development. 2005;132:2685-95.

72. Cebrià F, Bueno D, Reigada S, Romero R. Intercalary muscle cell renewal in planarian pharynx. Dev Genes Evol. 1999;209:249-53.

73. Cebrià F, Vispo M, Newmark P, Bueno D, Romero R. Myocyte differentiation and body wall muscle regeneration in the planarian Girardia tigrina. Dev Genes Evol. 1997;207:306-16.

74. Cebrià F. Planarian body-wall muscle: regeneration and function beyond a simple skeletal support. Front Cell Dev Biol. 2016;4:8.

75. Scimone ML, Cote LE, Reddien PW. Orthogonal muscle fibres have different instructive roles in planarian regeneration. Nature. 2017;126:1-22.

76. Ryan AK, Rosenfeld MG. POU domain family values: flexibility, partnerships, and developmental codes. Genes Dev. 1997;11:1207-25.

77. Gold DA, Gates RD, Jacobs DK. The early expansion and evolutionary dynamics of POU class genes. Mol Biol Evol. 2014;31:3136-47.

78. Nichols J, Zevnik B, Anastassiadis K, Niwa H, Klewe-Nebenius D, Chambers l, et al. Formation of pluripotent stem cells in the mammalian embryo depends on the POU transcription factor Oct4. Cell. 1998;95:379-91.

79. Takahashi K, Yamanaka S. Induction of pluripotent stem cells from mouse embryonic and adult fibroblast cultures by defined factors. Cell. 2006;126:663-76

80. Munoz-Marmol AM, Casali A, Miralles A, Bueno D, Bayascs JR, Romero R, et al. Characterization of platyhelminth POU domain genes: ubiquitous and specific anterior nerve cell expression of different epitopes of GtPOU-1. Mech Dev. 1998;76:127-40.

81. Wollesen T, McDougall C, Degnan BM, Wanninger A. POU genes are expressed during the formation of individual ganglia of the cephalopod central nervous system. EvoDevo. 2014;5:41.

82. Onal P, Grün D, Adamidi C, Rybak A, Solana J, Mastrobuoni G, et al. Gene expression of pluripotency determinants is conserved between mammalian and planarian stem cells. EMBO J. 2012;31:2755-69.

83. Scimone ML, Srivastava M, Bell GW, Reddien PW. A regulatory program for excretory system regeneration in planarians. Development. 2011;138:4387-98.

84. Wagner DE, Ho JJ, Reddien PW. Genetic regulators of a pluripotent adult stem cell system in planarians identified by RNAi and clonal analysis. Stem Cell. 2012;10:299-311.

85. Jager M, Quéinnec E, Houliston E, Manuel M. Expansion of the SOX gene family predated the emergence of the Bilateria. Mol Phylogenet Evol. 2006;39:468-77. 
86. Sarkar A, Hochedlinger K. The sox family of transcription factors: versatile regulators of stem and progenitor cell fate. Cell Stem Cell. 2013;12:15-30.

87. Vaquerizas JM, Kummerfeld SK, Teichmann SA, Luscombe NM. A census of human transcription factors: function, expression and evolution. Nat Rev Genet. 2009;10:252-63.

88. Seetharam A, Stuart GW. A study on the distribution of 37 well conserved families of $\mathrm{C} 2 \mathrm{H} 2$ zinc finger genes in eukaryotes. BMC Genom. 2013;14:420.

89. de Mendoza A, Sebé-Pedrós A, Šestak MS, Matejčić M, Torruella G, Domazet-Lošo T, et al. Transcription factor evolution in eukaryotes and the assembly of the regulatory toolkit in multicellular lineages. Proc Natl Acad Sci USA. 2013;110:E4858-66.

90. Demircan T, Berezikov E. The Hippo pathway regulates stem cells during homeostasis and regeneration of the flatworm Macrostomum lignano. Stem Cells Dev. 2013;22:2174-85.

91. Lin AYT, Pearson BJ. Yorkie is required to restrict the injury responses in planarians. PLoS Genet. 2017:13:e1006874.

92. Salvetti A, Rossi L, Lena A, Batistoni R, Deri P, Rainaldi G, et al. DjPum, a homologue of Drosophila Pumilio, is essential to planarian stem cell maintenance. Development. 2005;132:1863-74.

93. Koziol U, Marín M, Castillo E. Pumilio genes from the Platyhelminthes. Dev Genes Evol. 2008;218:47-53.

94. Nieto MA. The snail superfamily of zinc-finger transcription factors. Nat Rev Mol Cell Biol. 2002;3:155-66.

95. Soleimani VD, Yin H, Jahani-Asl A, Ming H, Kockx CEM, van ljcken WFJ, et al. Snail regulates MyoD binding-site occupancy to direct enhancer switching and differentiation-specific transcription in myogenesis. Mol Cell. 2012;47:457-68.

96. Amoutzias GD, Veron AS, Weiner J, Robinson-Rechavi M, BornbergBauer E, Oliver SG, et al. One billion years of bZIP transcription factor evolution: conservation and change in dimerization and DNA-binding site specificity. Mol Biol Evol. 2007;24:827-35.

97. Koga H, Hashimoto N, Suzuki DG, Ono H. A genome-wide survey of genes encoding transcription factors in Japanese pearl oyster Pinctada fucata: II. Tbx, Fox, Ets, HMG, NFkB, bZIP, and C2H2 zinc fingers. Zool Sci. 2013;30:858-67.

98. Umesono Y, Tasaki J, Nishimura Y, Hrouda M, Kawaguchi E, Yazawa S, et al. The molecular logic for planarian regeneration along the anteriorposterior axis. Nature. 2014;500:73-6.

99. Witchley JN, Mayer M, Wagner DE, Owen JH, Reddien PW. Muscle cells provide instructions for planarian regeneration. Cell Rep. 2013;4:633-41.

100. Koziol U, Brehm K. Recent advances in Echinococcus genomics and stem cell research. Vet Parasitol. 2015;213:92-102.

101. Sulgostowska T. The development of organ systems in cestodes. II. Histogenesis of the reproductive system in Hymenolepis diminuta (Rudolphi, 1819) (Hymenolepididae). Acta Parasitol Polonica. 1974;22:179-90.

102. Heldin CH, Miyazono K, Tendijke P. TGF-beta signalling from cell membrane to nucleus through SMAD proteins. Nature. 1997;390:465-71.

103. Derynck R, Zhang YE. Smad-dependent and Smad-independent pathways in TGF-beta family signalling. Nature. 2003;425:577-84

104. Freitas TC, Jung E, Pearce EJ. TGF- $\beta$ signaling controls embryo development in the parasitic flatworm Schistosoma mansoni. PLoS Pathog. 2007;3:e52.

105. Kenny NJ, Namigai EKO, Dearden PK, Hui JHL, Grande C, Shimeld SM. The Lophotrochozoan TGF- $\beta$ signalling cassette-diversification and conservation in a key signalling pathway. Int J Dev Biol. 2014;58:533-49.

106. Osman A, Niles EG, Verjovski-Almeida S, LoVerde PT. Schistosoma mansoni TGF- $\beta$ receptor II: role in host ligand-induced regulation of a schistosome target gene. PLoS Pathog. 2006;2:e54.

107. de Robertis EM, Sasai Y. A common plan for dorsoventral patterning in Bilateria. Nature. 1996;380:37-40.

108. Molina MD, Salo E, Cebrià F. Organizing the DV axis during planarian regeneration. Commun Integr Biol. 2011:4:498-500.

109. Molina MD, Neto A, Maeso I, Gómez-Skarmeta JL, Salo E, Cebrià F. Noggin and noggin-like genes control dorsoventral axis regeneration in planarians. Curr Biol. 2011;21:300-5.

110. Molina MD, Salo E, Cebrià F. The BMP pathway is essential for respecification and maintenance of the dorsoventral axis in regenerating and intact planarians. Dev Biol. 2007;311:79-94.
111. Orii $\mathrm{H}$, Watanabe K. Bone morphogenetic protein is required for dorsoventral patterning in the planarian Dugesia japonica. Dev Growth Differ. 2007:49:345-9.

112. Gaviño MA, Reddien PW. A Bmp/Admp regulatory circuit controls maintenance and regeneration of dorsal-ventral polarity in planarians. Curr Biol. 2011;21:294-9.

113. Reddien PW, Bermange A, Kicza A, Sánchez Alvarado A. BMP signaling regulates the dorsal planarian midline and is needed for asymmetric regeneration. Development. 2007;134:4043.

114. Range RC, Wei Z. An anterior signaling center patterns and sizes the anterior neuroectoderm of the sea urchin embryo. Development. 2016:143:1523-33.

115. Wei Z, Yaguchi J, Yaguchi S, Angerer RC, Angerer LM. The sea urchin animal pole domain is a Six3-dependent neurogenic patterning center. Development. 2009;136:1179-89.

116. Steinmetz PRH, Urbach R, Posnien N, Eriksson J, Kostyuchenko RP, Brena $C$, et al. Six3 demarcates the anterior-most developing brain region in bilaterian animals. EvoDevo. 2010;1:14

117. Koziol U, Brehm K. Anatomy and development of the larval nervous system in Echinococcus multilocularis. Front Zool. 2013;10:24.

118. Pineda D, Salo E. Planarian Gtsix3, a member of the Six/so gene family, is expressed in brain branches but not in eye cells. Mech Dev. 2002;2:169-73.

119. Wilson V, Schiller E. The neuroanatomy of Hymenolepis diminuta and $H$. nana. J Parasitol. 1969:55:261-70.

120. Webb RA. Putative neurosecretory cells of the cestode Hymenolepis microstoma. J Parasitol. 1976;62:756-60.

121. Reuter M, Gustafsson M. Neuronal signal substances in asexual multiplication and development in flatworms. Cell Mol Neurobiol. 1996;16:591-616.

122. Rivera AS, Weisblat DA. And Lophotrochozoa makes three: Notch/Hes signaling in annelid segmentation. Dev Genes Evol. 2008;219:37-43.

123. Shah C, Vangompel MJW, Naeem V, Chen Y, Lee T, Angeloni N, et al. Widespread presence of human BOULE homologs among animals and conservation of their ancient reproductive function. PLOS Genet. 2010;6:e1001022.

124. Kuales G, de Mulder K, Glashauser J, Salvenmoser W, Takashima $\mathrm{S}$, Hartenstein $\mathrm{V}$, et al. Boule-like genes regulate male and female gametogenesis in the flatworm Macrostomum lignano. Dev Biol. 2011;357:117-32.

125. Iyer $\mathrm{H}$, Issigonis M, Sharma PP, Extavour CGM, Newmark PA. A premeiotic function for boule in the planarian Schmidtea mediterranea. Proc Natl Acad Sci USA. 2016;113:E3509-18.

126. Steiner JK, Tasaki J, Rouhana L. Germline defects caused by Smed-boule RNA-interference reveal that egg capsule deposition occurs independently of fertilization, ovulation, mating, or the presence of gametes in planarian flatworms. PLoS Genet. 2016;12:e1006030.

127. Blake JA, Ziman MR. Pax genes: regulators of lineage specification and progenitor cell maintenance. Development. 2014;141:737-51.

128. Aloisio GM, Nakada Y, Saatcioglu HD, Peña CG, Baker MD, Tarnawa ED, et al. PAX7 expression defines germline stem cells in the adult testis. J Clin Investig. 2014;124:3929-44.

129. Blassberg RA, Felix DA, Tejada-Romero B, Aboobaker AA. PBX/extradenticle is required to re-establish axial structures and polarity during planarian regeneration. Development. 2013;140:730-9.

130. Takahashi H, Kamiya A, Ishiguro A, Suzuki AC, Saitou N, Toyoda A, et al. Conservation and diversification of Msx protein in metazoan evolution. Mol Biol Evol. 2008;25:69-82.

131. Ramos C, Robert B. msh/Msx gene family in neural development. Trends Genet. 2005;21:624-32.

132. Galle S, Yanze N, Seipel K. The homeobox gene Msx in development and transdifferentiation of jellyfish striated muscle. Int J Dev Biol. 2005:49:961-7.

133. Shimeld SM, McKay IJ, Sharpe PT. The murine homeobox gene Msx-3 shows highly restricted expression in the developing neural tube. Mech Dev. 1996;55:201-10

134. Saudemont A, Dray N, Hudry B, Le Gouar M, Vervoort M, Balavoine G. Complementary striped expression patterns of NK homeobox genes during segment formation in the annelid Platynereis. Dev Biol. 2008;317:430-43. 
135. Mannini L, Deri P, Gremigni V, Rossi L, Salvetti A, Batistoni R. Two $m s h / m s x$-related genes, Djmsh 1 and Djmsh2, contribute to the early blastema growth during planarian head regeneration. Int J Dev Biol. 2008;52:943-52

136. Le Bouffant R, Souquet B, Duval N, Duquenne C, Herve R, Frydman $\mathrm{N}$, et al. Msx1 and Msx2 promote meiosis initiation. Development. 2011;138:5393-402.

137. Nallasamy S, Li Q, Bagchi MK, Bagchi IC. Msx homeobox genes critically regulate embryo implantation by controlling paracrine signaling between uterine stroma and epithelium. PLoS Genet. 2012;8:e1002500-13.

138. Ryan JF, Burton PM, Mazza ME, Kwong GK, Mullikin JC, Finnerty JR. The cnidarian-bilaterian ancestor possessed at least 56 homeoboxes: evidence from the starlet sea anemone, Nematostella vectensis. Genome Biol. 2006;7:R64.

139. Zhong Y-F, Butts T, Holland PW. HomeoDB: a database of homeobox gene diversity. Evol Dev. 2008;10:516-8.

140. Zhong Y-F, Holland P. HomeoDB2: functional expansion of a comparative homeobox gene database for evolutionary developmental biology. Evol Dev. 2011;13:567-8.

141. Homminga I, Pieters R, Meijerink JPP. NKL homeobox genes in leukemia. Leukemia. 2011;26:572-81.

142. Knirr S, Azpiazu N, Frasch M. The role of the NK-homeobox gene slouch (S59) in somatic muscle patterning. Development. 1999;126:4525-35.

143. Lu Z, Sessler F, Holroyd N, Hahnel S, Quack T, Berriman M, et al. Schistosome sex matters: a deep view into gonad-specific and pairingdependent transcriptomes reveals a complex gender interplay. Sci Rep. 2016;6:1-14.

144. Acampora D, Gulisano M, Broccoli V, Simeone A. Otx genes in brain morphogenesis. Prog Neurobiol. 2001;64:69-95.

145. Umesono Y, Watanabe K, Agata K. Distinct structural domains in the planarian brain defined by the expression of evolutionarily conserved homeobox genes. Dev Genes Evol. 1999;209:31-9.

146. Cebrià F, Kudome T, Nakazawa M, Mineta K, Ikeo K, Gojobori T, et al. The expression of neural-specific genes reveals the structural and molecular complexity of the planarian central nervous system. Mech Dev. 2002;116:199-204.

147. Lapan SW, Reddien PW. Transcriptome analysis of the planarian eye identifies ovo as a specific regulator of eye regeneration. Cell Rep. 2012;2:294-307.

148. Hassan B, Li L, Bremer KA, Chang WR, Pinsonneault J, Vaessin H. Prospero is a panneural transcription factor that modulates homeodomain protein activity. Proc Natl Acad Sci USA. 1997;94:10991-6.

149. Lai S-L, Doe CQ. Transient nuclear Prospero induces neural progenitor quiescence. eLife. 2014;3:379-82.

150. Choksi SP, Southall TD, Bossing T, Edoff K, de Wit E, Fischer BE, et al. Prospero acts as a binary switch between self-renewal and differentiation in Drosophila neural stem cells. Dev Cell. 2006;11:775-89.

151. Georges A, Auguste A, Bessiere L, Vanet A, Todeschini AL, Veitia RA. FOXL2: a central transcription factor of the ovary. J Mol Endocrinol. 2013;52:R17-33

152. Laumer CE, Hejnol A, Giribet G. Nuclear genomic signals of the "microturbellarian" roots of platyhelminth evolutionary innovation. eLife. 2015;4:e05503.

153. Egger B, Lapraz F, Tomiczek B, Müller S, Dessimoz C, Girstmair J, et al. A transcriptomic-phylogenomic analysis of the evolutionary relationships of flatworms. Curr Biol. 2015;25:1347-53.

154. Martín-Durán JM, Egger B. Developmental diversity in free-living flatworms. EvoDevo. 2012;3:7

155. Wang J, Collins J. Identification of new markers for the Schistosoma mansoni vitelline lineage. Int J Parasitol. 2016:46:405-10.

156. Vasudevan S, Starostina NG, Kipreos ET. The Caenorhabditis elegans cellcycle regulator ZYG-11 defines a conserved family of CUL-2 complex components. EMBO Rep. 2007:8:279-86.
157. Liu J, Vasudevan S, Kipreos ET. CUL-2 and ZYG-11 promote meiotic anaphase II and the proper placement of the anterior-posterior axis in C. elegans. Development. 2004;131:3513-25.

158. Blockus H, Chédotal A. Slit-Robo signaling. Development. 2016;143:3037-44.

159. Petersen CP, Reddien PW. Wnt signaling and the polarity of the primary body axis. Cell. 2009:139:1056-68.

160. International Helminth Genomes Consortium, Coghlan A, Mitreva M, Berriman M. Comparative genomics of the major parasitic worms. Nat Genet. 2018 (in press).

161. Nelson PA, Buggs RJA. Next generation apomorphy: the ubiquity of taxonomically restricted genes. In: Olson PD, Hughes J, Cotton JA, editors. Next generation systematics. Cambridge: Cambridge University Press; 2016. p. 237-63.

162. Khalturin $\mathrm{K}$, Hemmrich $\mathrm{G}$, Fraune $\mathrm{S}$, Augustin R. More than just orphans: are taxonomically-restricted genes important in evolution? Trends Genet. 2009;25:404-13.

163. Domínguez MF, Koziol U, Porro V, Costábile A, Estrade S, Tort JF, et al. A new approach for the characterization of proliferative cells in cestodes. Exp Parasitol. 2014:138:25-9.

164. Collins JI, Wendt GR, lyer H, Newmark PA. Stem cell progeny contribute to the schistosome host-parasite interface. eLife. 2016:5:e12473.

165. van Wolfswinkel JC, Wagner DE, Reddien PW. Single-cell analysis reveals functionally distinct classes within the planarian stem cell compartment. Cell Stem Cell. 2014;15:326-39.

166. Voge M. Development of Hymenolepis microstoma (Cestoda: Cyclophyllidea) in the intermediate host Tribolium confusum. J Parasitol. 1964;50:77-80.

167. Hunt M, Kikuchi T, Sanders M, Newbold C, Berriman M, Otto TD. REAPR: a universal tool for genome assembly evaluation. Genome Biol. 2013;14:R47.

168. Zerbino DR. Using the Velvet de novo assembler for short-read sequencing technologies. New York: Wiley Online Library; 2010.

169. Boetzer M, Henkel CV, Jansen HJ, Butler D, Pirovano W. Scaffolding preassembled contigs using SSPACE. Bioinformatics. 2010;27:578-9.

170. Nadalin F, Vezzi F, Policriti A. GapFiller: a de novo assembly approach to fill the gap within paired reads. BMC Bioinform. 2012;13:S8.

171. Kurtz S, Phillippy A, Delcher AL, Smoot M, Shumway M, Antonescu $C$, et al. Versatile and open software for comparing large genomes. Genome Biol. 2004:5:R12-9.

172. Assefa S, Keane TM, Otto TD, Newbold C, Berriman M. ABACAS: algorithm-based automatic contiguation of assembled sequences. Bioinformatics. 2009;25:1968-9.

173. Keller O, Kollmar M, Stanke M, Waack S. A novel hybrid gene prediction method employing protein multiple sequence alignments. Bioinformatics. 2011;27:757-63.

174. Trapnell C, Roberts A, Goff L, Pertea G, Kim D, Kelley DR, et al. Differential gene and transcript expression analysis of RNA-seq experiments with TopHat and Cufflinks. Nat Protoc. 2012;7:562-78.

175. Love MI, Huber W, Anders S. Moderated estimation of fold change and dispersion for RNA-seq data with DESeq2. Genome Biol. 2014;15:31-41.

176. du Plessis L, Skunca N, Dessimoz C. The what, where, how and why of gene ontology-a primer for bioinformaticians. Brief Bioinform. $2011 ; 12: 723-35$

177. Untergasser A, Cutcutache I, Koressaar T, Ye J, Faircloth BC, Remm M, et al. Primer3-new capabilities and interfaces. Nucleic Acids Res. 2012;40:e115-5.

178. Riddiford N, Olson PD. Wnt gene loss in flatworms. Dev Genes Evol. 2011;221:187-97. 